NBER WORKING PAPER SERIES

\title{
FREE TO CHOOSE: PROMOTING CONSERVATION BY RELAXING OUTDOOR WATERING RESTRICTIONS
}

\author{
Anita Castledine \\ Klaus Moeltner \\ Michael Price \\ Shawn Stoddard \\ Working Paper 20362 \\ http://www.nber.org/papers/w20362 \\ NATIONAL BUREAU OF ECONOMIC RESEARCH \\ 1050 Massachusetts Avenue \\ Cambridge, MA 02138 \\ July 2014
}

\begin{abstract}
Part of this research was conducted while Moeltner was a Visiting Scholar at the Luskin Center for Innovation, School of Public Affairs, University of California, Los Angeles. An earlier version of this manuscript was presented at a workshop on "The Identification of Causal Effects in Environmental and Energy Economics," which was hosted by the Howard H. Baker Jr. Center for Public Policy at the University of Tennessee. The authors would like to thank the Baker Center for hosting the workshop and the Journal of Economic Behavior and Organization for dedicating a special issue of the journal for papers presented at the workshop. We would also like to thank Christian Vossler, Mary Evans, and Matt Kotchen for organizing the workshop, and Roger von Haefen and participants at the workshop for providing us comments that have greatly improved the manuscript. The views expressed herein are those of the authors and do not necessarily reflect the views of the National Bureau of Economic Research.
\end{abstract}

NBER working papers are circulated for discussion and comment purposes. They have not been peerreviewed or been subject to the review by the NBER Board of Directors that accompanies official NBER publications.

(C) 2014 by Anita Castledine, Klaus Moeltner, Michael Price, and Shawn Stoddard. All rights reserved. Short sections of text, not to exceed two paragraphs, may be quoted without explicit permission provided that full credit, including (C) notice, is given to the source. 
Free to Choose: Promoting Conservation by Relaxing Outdoor Watering Restrictions

Anita Castledine, Klaus Moeltner, Michael Price, and Shawn Stoddard

NBER Working Paper No. 20362

July 2014

JEL No. C11,C30,Q2,Q25,Q58

\begin{abstract}
$\underline{\text { ABSTRACT }}$
Many water utilities use outdoor watering restrictions based on assigned weekly watering days to promote conservation and delay costly capacity expansions. We find that such policies can lead to unintended consequences - customers who adhere to the prescribed schedule use more water than those following a more flexible irrigation pattern. For our application to residential watering in a high-desert environment, this "rigidity penalty" is robust to an exogenous policy change that allowed an additional watering day per week. Our findings contribute to the growing literature on leakage effects of regulatory policies. In our case inefficiencies arise as policies limit the extent to which agents can temporally re-allocate actions.
\end{abstract}

Anita Castledine

Public Utilities Council of Nevada

1150 East Williams Street

Carson City NV 89701

acastledine@puc.nv.gov

Klaus Moeltner

Department of Agricultural

and Applied Economics

208 Hutcheson Hall

Blacksburg VA 24061

moeltner@vt.edu
Michael Price

Department of Economics

Andrew Young School of Policy Studies

Georgia State University

P.O. Box 3992

Atlanta, GA 30302-3992

and NBER

mprice25@gsu.edu

Shawn Stoddard

Truckee Meadows Water Authority

1355 Capital Boulevard

Reno NV 89502

sstoddard@tmwa.com 


\title{
Free to choose: Promoting conservation by relaxing outdoor watering restrictions
}

\author{
A. Castledine ${ }^{\mathrm{a}}$, K. Moeltner ${ }^{\mathrm{b}, 1, *}$, M.K. Price $^{\mathrm{c}}$, S. Stoddard $^{\mathrm{d}}$ \\ ${ }^{a}$ Public Utilities Commission of Nevada, 1150 E. William Street, Carson City, NV 89701-3109 \\ ${ }^{b}$ Department of Agricultural and Applied Economics, Virginia Tech, 208 Hutcheson Hall, Blacksburg, VA 24061 \\ ${ }^{c}$ Department of Economics, Andrew Young School of Policy Studies, Georgia State University, and NBER, P.O. \\ Box 3992, Atlanta, GA 30302-3992 \\ ${ }^{d}$ Truckee Meadows Water Authority, 1355 Capital Blvd., Reno, NV 89502
}

\begin{abstract}
Many water utilities use outdoor watering restrictions based on assigned weekly watering days to promote conservation and delay costly capacity expansions. We find that such policies can lead to unintended consequences - customers who adhere to the prescribed schedule use more water than those following a more flexible irrigation pattern. For our application to residential watering in a high-desert environment, this "rigidity penalty" is robust to an exogenous policy change that allowed an additional watering day per week. Our findings contribute to the growing literature on leakage effects of regulatory policies. In our case inefficiencies arise as policies limit the extent to which agents can temporally re-allocate actions.
\end{abstract}

Keywords: Outdoor watering, water conservation, multi-equation system, Bayesian estimation, posterior simulation JEL classifications: C11, C30, Q25, Q58

\section{Introduction}

Water consumption across the globe has tripled in the last 50 years, and is expected to continue to rise rapidly. Water scarcity is expected to be further exacerbated by global warming via prolonged droughts and increasing system losses (Cromwell et al., 2007). The United Nations predicts that by 2030 almost half of the world's population will be living in areas of high water stress

${ }^{*}$ Corresponding author, work phone: (540)231-8249, fax: (540)231-7417

Email addresses: acastledine@puc.nv.gov (A. Castledine), moeltner@vt.edu (K. Moeltner), mprice21@utk.edu (M.K. Price), sstoddard@tmwa.com (S. Stoddard)

${ }^{1}$ Part of this research was conducted while Moeltner was a Visiting Scholar at the Luskin Center for Innovation, School of Public Affairs, University of California, Los Angeles. An earlier version of this manuscript was presented at a workshop on "The Identification of Causal Effects in Environmental and Energy Economics," which was hosted by the Howard H. Baker Jr. Center for Public Policy at the University of Tennessee. The authors would like to thank the Baker Center for hosting the workshop and the Journal of Economic Behavior and Organization for dedicating a special issue of the journal for papers presented at the workshop. We would also like to thank Christian Vossler, Mary Evans, and Matt Kotchen for organizing the workshop, and Roger von Haefen and participants at the workshop for providing us comments that have greatly improved the manuscript. 
(U.N. World Water Assessment Programme, 2009) and nearly every region in the United States has experienced drought induced water shortages over the last five to ten years (U.S. Environmental Protection Agency, 2008a). The sustainable provision of water is thus one of the most critical challenges facing policy-makers in both the U.S. and world at large.

Residential households consume close to two thirds of all publicly supplied water in the United States (U.S. Environmental Protection Agency, 2002). On average, approximately $15 \%$ of residential use is allocated to landscape and lawn irrigation. However, in the arid west and south this proportion can be as large as 30-35\%. In total, an estimated seven billion gallons of publicly provided water are allocated for this purpose daily (U.S. Environmental Protection Agency, 2008b,c). Policy makers and water utilities have thus directed considerable efforts to the management of residential outdoor irrigation. In most cases these efforts focus on outdoor watering restrictions (OWRs) that limit the timing, length, and frequency of sprinkler use. ${ }^{2}$

Such OWRs have been implemented in many areas within and outside the United States. As noted in Table A1 in Appendix A, most of these regimes limit weekly watering to between one and three assigned days determined by street address. Moreover, most of these regimes (see, e.g., San Antonio or the State of Georgia) follow a paradigm whereby the number of assigned days is reduced under progressively severe drought conditions.

To date, economists have primarily focused on two aspects of OWR policies: (i) the overall impact on water demand, and (ii) the welfare effects for residential consumers. For example, Shaw and Maidment (1987) find that a one-per-five days watering restriction reduced overall demand by 3-5\% during the 1984-85 drought years in Austin, Texas. Renwick and Green (2000) examine monthly consumption for eight California water utilities during the 1985-92 drought period and find that OWRs of a general nature generated an approximate $30 \%$ reduction in use. The second set of studies focus on welfare implications of OWRs and other drought-related water use restrictions. Typically, these studies employ non-market valuation techniques to elicit households' willingnessto-pay (WTP) to avoid such restrictions (Griffin and Mjelde, 2000; Hensher et al., 2006), or an increased risk of future restrictions (Howe and Smith, 1994; Griffin and Mjelde, 2000).

Despite the growing importance of OWRs as a Demand-Side Management (DSM) intervention, surprisingly little is known about the relative performance of different OWR implementation strategies. Given that OWRs vary substantially across communities, such omission is particularly noteworthy. This study seeks to fill this gap in the literature. We examine daily consumption data for thousands of customers in the Reno / Sparks area of Northern Nevada during the 2008 and 2010 summer months. This temporal break affords a unique opportunity to examine an exogenous policy change in OWRs that allowed households an added assigned watering day each week during the 2010 watering season.

Our analysis uncovers an unintended consequence associated with the use of assigned watering schedules - weekly water use and peaks are significantly higher during weeks that include all officially assigned watering days compared to weeks with an equal number of watering days but a more flexible pattern of use. These "rigidity penalties" are substantial, amounting to 20-25 percent of weekly

\footnotetext{
${ }^{2}$ Given the price inelastic nature of water demand, such regulatory interventions are more effective means to influence consumption than price-based policies (Renwick and Green, 2000; Mansur and Olmstead, 2007; Olmstead et al., 2007; Worthington and Hoffman, 2008). Furthermore, there are generally fewer equity concerns and less political resistance to OWRs than to price-based policies (Renwick and Archibald, 1998; Timmins, 2003; Brennan et al., 2007).
} 
consumption and 30-40 percent of weekly peaks for the typical customer. Although the 2010 policy change had a noticeable impact on daily peaks, it had no discernible effect on weekly consumption of the associated "rigidity penalties".

Viewed in its totality, our data call into question the efficacy of OWRs that limit watering to assigned days. In this regard, our analysis extends prior work exploring the unintended consequences of policy actions that either introduce heterogeneity in standards across factories or regions (Felder and Rutherford, 1993; Fowlie, 2009) or nested state and federal regulation (McGuinness and Ellermann, 2008; Goulder and Stavins, 2011; Goulder et al., 2012). ${ }^{3}$ Whereas the cited work focuses on leakages that arise through the spatial reallocation of actions, our paper highlights that a similar phenomena can arise if policies limit the extent to which agents can temporally reallocate actions. In our setting, adherence to the official water schedule requires households to ignore time-varying conditions such as high wind events that reduce the efficiency of irrigation systems.

\section{Empirical Background and Data}

Water provision in the Reno / Sparks urban area is managed by the Truckee Meadows Water Authority (TMWA), a non-profit, community-owned public utility. TMWA first implemented OWRs in 1992 in reaction to a prolonged drought. They became permanent in 1996 to guard against future droughts and assure adequate flows of the Truckee River. The watering regulations allow sprinkler use during the morning and evening of assigned days determined by the last digit of a resident's address. ${ }^{4}$ Prior to 2010 , the policy allowed households two assigned watering days per week. During the 2010 watering season, the OWR was relaxed and allowed a third weekly watering day. These OWRs are only mildly enforced with infrequent water patrols and nominal fines (up to $\$ 75)$ for repeated violations in the same calendar year.

In 2008 TMWA initiated the collection of daily water consumption data for a large, representative sample of customers. Meter readings were obtained via nightly drive-by's using remote sensing devices. Two teams of readers covered the same route for 63 consecutive days between June 22 and August 23, 2008. ${ }^{5}$ The same exercise was repeated between June 20 and August 21, 2010 although the routes differed somewhat from the 2008 itineraries due to construction activities. ${ }^{6}$

Overall, we observe approximately 1.9 million daily meter readings from approximately 20,000 unique residential customers. In preparing the final data set, we eliminate premises with ownership changes or multiple ownerships during a given year's research period. We further drop households with a total of 14 or more readings of zero consumption and customers with four or more consecutive

\footnotetext{
${ }^{3}$ Unintended consequences have also been documented in a number of other settings. For example, Davis and Kahn (2010) show that while trade in used vehicles between Mexico and the United States following the passage of NAFTA lowers average vehicle emissions per mile in both countries, aggregate greenhouse gas emissions rise due to lower retirement rates of used cars in Mexico. Bento et al. (2011) show how policy changes in California that allowed single-occupancy, ultra-low emission vehicles access to HOV lanes significantly increased travel times for carpoolers and had no impact on travel times for those in non-HOV lanes.

${ }^{4}$ There are no restrictions on watering via hand-held hoses.

${ }^{5}$ The readings were obtained between the hours of $9 \mathrm{pm}$ and $3 \mathrm{am}$. According to TMWA, the vast majority of households complete watering by $9 \mathrm{pm}$.

${ }^{6}$ Drivers were instructed to proceed no slower than the posted speed limit to assure adequate spatial coverage. While this resulted in a large number of customers being included in the sample, it also generated some missing readings due to parked vehicles or other obstacles preventing a clean line-of-sight. Therefore, a completely uninterrupted series of readings is available only for a small subset of the sample.
} 
zero readings anywhere in the daily series to lower the risk of including non-permanent residences and vacation homes. These cleaning steps truncated the set of eligible residents by approximately $15 \%$ for each year.

Given our focus on weekly watering frequencies, only weeks for which we obtain a full set of readings for a given household are usable. Further, to identify a household's watering days and weekly watering patterns, a minimum number of intact weeks (MIW) was required. Yet, to maximize the number of residents present in both sample periods, we had to consider the relationship between the stringency of our MIW criterion and the size of our overlap sample. In balancing these requirements we settle for an MIW threshold of five full weeks of daily readings. After eliminating a few isolated cases with obvious water leaks or missing information on basic building characteristics we generate a final sample that includes 52,666 weekly observations from 8,747 residents for 2008 and 48,573 observations from 7,652 unique residents for 2010. Of these households, 1,766 appear in both the 2008 and 2010 samples and comprise our "overlap" sample. Table 1 shows the distribution of intact weeks for both the full and overlap samples by year.

Table 1: Sample sizes for 2008 and 2010

\begin{tabular}{|c|c|c|c|c|c|c|c|c|}
\hline \multirow[b]{2}{*}{ intact weeks } & \multicolumn{4}{|c|}{2008} & \multicolumn{4}{|c|}{2010} \\
\hline & HHs & $\%$ & obs & $\%$ & $\mathrm{HHs}$ & $\%$ & obs & $\%$ \\
\hline 5 & 3,567 & $40.8 \%$ & 17,835 & $33.9 \%$ & 2,084 & $27.2 \%$ & 10,420 & $21.5 \%$ \\
\hline 6 & 2,284 & $26.1 \%$ & 13,704 & $26.0 \%$ & 826 & $10.8 \%$ & 4,956 & $10.2 \%$ \\
\hline 7 & 2,041 & $23.3 \%$ & 14,287 & $27.1 \%$ & 4,739 & $61.9 \%$ & 33,173 & $68.3 \%$ \\
\hline 8 & 855 & $9.8 \%$ & 6,840 & $13.0 \%$ & 3 & $0.0 \%$ & 24 & $0.0 \%$ \\
\hline Total & 8,747 & $100.0 \%$ & 52,666 & $100.0 \%$ & 7,652 & $100.0 \%$ & 48,573 & $100.0 \%$ \\
\hline & \multicolumn{4}{|c|}{ Overlap*, 2008} & \multicolumn{4}{|c|}{ Overlap, 2010} \\
\hline intact weeks & HHs & $\%$ & obs & $\%$ & $\mathrm{HHs}$ & $\%$ & obs & $\%$ \\
\hline 5 & 679 & $38.4 \%$ & 3,395 & $31.6 \%$ & 1,061 & $60.1 \%$ & 5,305 & $52.4 \%$ \\
\hline 6 & 435 & $24.6 \%$ & 2,610 & $24.3 \%$ & 121 & $6.9 \%$ & 726 & $7.2 \%$ \\
\hline 7 & 463 & $26.2 \%$ & 3,241 & $30.1 \%$ & 584 & $33.1 \%$ & 4,088 & $40.4 \%$ \\
\hline 8 & 189 & $10.7 \%$ & 1,512 & $14.1 \%$ & 0 & $0.0 \%$ & 0 & $0.0 \%$ \\
\hline Total & 1,766 & $100.0 \%$ & 10,758 & $100.0 \%$ & 1,766 & $100.0 \%$ & 10,119 & $100.0 \%$ \\
\hline
\end{tabular}

The top half of Table 2 depicts basic household characteristics for the two full samples. The 2010 sample comprises, on average, slightly smaller and older properties. There is also a $44 \%$ decline in average tax-assessed property value from 2008 to 2010 reflecting the severe economic downturn in Nevada over the sample period.

We combine our household data with the following basic climate indicators: average, minimum, and maximum daily temperature (in ${ }^{\circ} \mathrm{F}$ ), average wind speed (over 24 hourly measurements, in knots), and maximum sustained wind speed (in knots, measured for ten minutes every hour). As is common in arid high-dessert climates, there were no noteworthy rainfall events during our sampling periods. Climate statistics are shown in the bottom half of Table 2. Although the summer of 2010 was slightly cooler than the summer of 2008 , the wind statistics are very similar for the two sampling 
periods.

Table 2: Household and climate characteristics

\begin{tabular}{ccccccccc}
\hline & \multicolumn{4}{c}{2008} & \multicolumn{5}{c}{2010} \\
& mean & std. & min. & max. & mean & std. & min. & max. \\
\hline & & & & & & & & \\
age & 20.9 & 17.6 & 1.0 & 104.0 & 23.1 & 16.4 & 2.0 & 106.0 \\
lot size (1000 sqft) & 10.1 & 7.0 & 0.0 & 49.7 & 7.6 & 3.3 & 0.0 & 48.8 \\
sqft (1000s) & 2.0 & 0.8 & 0.5 & 15.2 & 1.8 & 0.6 & 0.5 & 7.7 \\
value (\$10,000s) & 270.5 & 160.2 & 69.4 & 2637.4 & 150.7 & 65.6 & 33.8 & 762.8 \\
fixtures & 12.0 & 3.4 & 0.0 & 64.0 & 11.1 & 2.8 & 0.0 & 27.0 \\
bedrms & 3.3 & 0.9 & 0.0 & 23.0 & 3.2 & 0.7 & 0.0 & 8.0 \\
bathrms. & 2.4 & 0.7 & 0.0 & 16.0 & 2.2 & 0.6 & 0.0 & 6.0 \\
& & & & & & & & \\
avg. temp (F) & 77.9 & 3.3 & 69.4 & 84.2 & 75.8 & 4.7 & 61.7 & 85.4 \\
min. temp & 59.9 & 3.5 & 53.1 & 66.0 & 58.9 & 4.8 & 44.6 & 69.1 \\
max. temp & 95.7 & 3.0 & 89.1 & 102.0 & 92.8 & 5.2 & 78.8 & 102.2 \\
avg. wind (knots) & 5.2 & 1.4 & 2.8 & 9.3 & 5.7 & 1.3 & 2.5 & 8.3 \\
max. wind & 16.2 & 4.2 & 7.0 & 29.9 & 16.8 & 4.2 & 8.9 & 32.1 \\
max. gust & 23.3 & 4.1 & 15.0 & 30.9 & 24.5 & 5.0 & 14.0 & 37.9 \\
\hline
\end{tabular}

\section{Identification of Policy Effects}

\subsection{Definition of Treatments}

We aim at identifying the impact of two design features of the Truckee Meadows OWRs on weekly water use and peak (maximum daily consumption in a given week) ${ }^{7}$ : (i) the total number of permissible watering days per week, and (ii) the "pinning" of the allowable number of days to specific days of the week (say, Wednesday, Saturday), versus letting households choose their watering days in a more flexible fashion.

For the former objective, we hypothesize that granting more watering days will induce a more even distribution of weekly irrigation, and thus reduce weekly peaks for the typical household. In addition, this smoother distribution, by reducing the gap between permitted days, may curb losses due to runoff and evaporation, as households are less likely to over-soak their lawn on assigned days.

For the latter objective, we separate weekly watering patterns into three categories: (i) "Schedule" $(S)$, (ii) "Schedule-plus" $(S P)$, and (iii) "Off-schedule" $(O S)$. The first group comprises weeks with watering patterns that correspond exactly to the assigned TMWA schedule. The second category describes weeks that include all assigned days, plus some additional ("illegal") days of outdoor use. The third group exhibits the most varied weekly watering patterns, with the common feature of non-watering on at least one of the assigned days. For ease of exposition we will at times

\footnotetext{
${ }^{7}$ System-wide consumption peaks are important to utilities as they are closely related to the cost of water provision. Specifically, lower peak demand can be satisfied via stored water, distributed by gravity. Storage units can then be replenished at night at lower pumping costs. In contrast, high peak use forces daytime pumping, when electricity costs are highest. If this occurs frequently, the utility may have to undergo costly capacity expansions for water storage. Therefore, a utility generally tries to implement water use policies that reduce daily peaks at the household level.
} 
combine the first two groups under the heading "Schedule-based" (SB). Thus, $S \cup S P=S B$, and $S B \cup O S=$ entire sample. This centers the analytical focus squarely on the degree to which the official schedule influences or "guides" irrigation patterns.

We hypothesize that $S$ types are nudged inadvertently towards wasteful behavior for two main reasons: First, they face the "large gaps" problem mentioned above, which can lead to over-watering and corresponding losses to runoff and evaporation. Second, adherence to the official schedule requires that such households ignore time-varying natural conditions such as (common) high wind events that can further exacerbate irrigation inefficiency. Both effects are likely to increase weekly consumption and, especially, weekly peaks.

In comparison, $S P$ types may be less prone to over-watering, as they distribute weekly irrigation over more-than-permitted days, but may still experience wind losses in their persistence to incorporate the assigned days. In contrast, we surmise that $O S$ types pay the least attention to the official schedule, and more attention to their yard's actual water needs and / or random fluctuations in weather conditions. This makes them the most disobedient, but perhaps also the most efficient TMWA customers.

In summary, we set forth to explore whether compliance with Reno's OWR policy introduces unintended consequences that compromise conversation aims. We will henceforth refer to water losses induced by the day-of-week assignment as "rigidity effect".

\subsection{Identification strategy}

We have exogenous variation in the number of permitted watering days - the policy change from two to three assigned days between 2008 and 2010. Ideally, we would have also been able to exogenously randomize the flexibility with which a household can allocate these days over the course of a week, i.e. assignment to $S, S P$, and $O S$ categories. Unfortunately, such exogenous policy variation did not occur during our research period.

Instead, we rely upon an alternate strategy for identification - other exogenous shocks that sort a given household into one type or other in an given week. Conditional on the existence of such shocks we can then exploit both cross-sectional and within household variation in weekly watering patterns to estimate the rigidity effect. This is because there are relatively few customers that follow the same weekly irrigation strategy $(S, S P$, or $O S)$ for the entire observation period. Most households display a mixed pattern of weekly irrigation, both in terms of frequency and timing. Therefore, identification can draw on both within and between household variation.

The challenge at hand is thus to (i) identify plausible exogenous drivers that induce customers to change watering patterns, and (ii) convincingly rule out confounding effects that could drive both weekly watering patterns and outcomes of interest, i.e. weekly use and peak.

With respect to exogenous factors we provide some evidence in the empirical section that $S B$ versus $O S$ choices are likely driven by randomly fluctuating daily wind patterns. Specifically, a given household may want to avoid wind-induced water losses - a common problem in this rain shadow / foothill location - by transferring watering events from a windy day to the next calm day. For the Reno/Sparks case this usually means foregoing the evening application and instead watering on the next (potentially unassigned) day. Inter-household differences in "wind awareness" or ability to flexibly manipulate irrigation systems then drives much of the observed cross-household variation in adherence to the official schedule. Naturally, some customers may also be intrinsically more reluctant to break the official rules, and may require "stronger wind shocks" to transfer watering to an off-day. This would add additional cross-sectional variation in observed behavior. 
In addition, there may be intra-household, time-varying differences in the daily ability to react to the threat of irrigation losses due to wind. For example, the entire household or the person in charge of the irrigation system may not be at home or unavailable on a given day to adjust the system. Similarly, on a given day the household may anticipate being unable to irrigate the next morning, and thus be reluctant to skip that day's evening application despite windy conditions. This would explain intra-household variations in the observed weekly irrigation patterns.

Regarding potentially confounding effects, our econometric specification controls for unobserved, invariant household effects, as well as weekly climate conditions. Therefore, the main concern in this respect would be confounding effects that vary both over time and across households. Most notably, one might surmise that whenever a household anticipates a week with high water need, it may switch to a more conservative watering pattern consistent with official regulations to lower the risk of fines. This would confound any causal link between the degree of adherence to the official schedule and water use. This conjecture builds on two underlying assumptions: (i) Households' weekly irrigation needs change from week to week in a heterogeneous fashion, and (ii) households care about enforcement and fines. We argue that neither one is very likely.

To start, the most plausible reason that could drive a sudden need to use more water in a given week for irrigation purposes would be an extreme climate event, such as the anticipation of a very hot or dry week. Perhaps some households are more vulnerable to such extreme events than others, given vegetation cover, soil quality, and other landscape-related features. However, as is evident from Table 2 the local climate during our summer research period is uniformly hot and dry. There is not a single day of precipitation, and the daily temperature range is quiet narrow. The only variation comes through daily and rather random wind patterns, and those cannot be anticipated on a weekly basis. Thus, it is rather unlikely that any given customer experiences pronounced changes in weekly irrigation demand over our research period.

In addition, it is equally unlikely that the threat of a penalty would induce customers to switch from a flexible to a compliant weekly pattern, even if such heterogeneous, time-varying changes in water need existed. As stated above, the enforcement of the official watering schedule is very lenient, and fines are nominal. A household receives two warnings for blatant violations before a fine of $\$ 75$ is issued. Thus, it is rather unlikely that the threat of low fine, collected with low probability, is sufficient to induce a change in behavior, irrespective of weekly water need.

Appendix B provides further evidence against this "comply if anticipated use is high" hypothesis. In summary, we feel confident to proceed with our analysis even in absence of an ideal setting with exogenous policy variation for all treatments of interest.

\section{Descriptive Analysis}

\subsection{Classification of weekly irrigation patterns}

Establishing a link between consumption and weekly watering patterns requires the identification of outdoor watering events for a given household and day. Specifically, our objective is to sort the daily observations for each household into two categories: (i) days with some outdoor water use, and (ii) days with indoor-only water use.

This categorization is challenging since we only observe total daily use rather than usage for different purposes. Ideally, outdoor watering days should be clearly identifiable as pronounced spikes in a customer's series of observed consumption days. However, the distinction between categories becomes blurred for households with limited need for outdoor watering or high fluctuations 
in indoor use. We therefore use a series of household-specific $K$-means clustering algorithms (MacQueen, 1967) to sort daily observations into a low use ("indoor only") and high use ("indoor plus some outdoor watering") category. The details of this identification strategy are given in Appendix B.

\subsection{Descriptive Results}

Our analysis of OWR design effects requires aggregating the daily sample to a weekly format. Table 3 provides a summary of cell counts and sample percentages for the different week-type categories and watering frequencies. For ease of exposition we combine $S$ and $S P$ weeks into the broader $S B$ category, as defined above. ${ }^{8}$ The sparsely populated weekly frequencies of five and higher are captured as a single " $>4$ " category. The first half of the table shows results for 2008, while the second provides summaries for 2010. The table has three blocks of rows, corresponding to $S B$ weeks, $O S$ weeks, and the combined sample. The "percent of sample" column relates row counts to the entire sample size for each year. For example, $S B$ weeks with twice watering (i.e. the $S$ group by our definition above) comprise $27.5 \%$ of the entire 2008 sample. Overall, watering patterns that are perfectly compliant with the official schedule comprise the largest sample share and account for just over a quarter of all sample weeks.

The "percent all within" column reports the percentage share for a given row count that corresponds to households that have all their observations in that very category. For example, approximately $42.8 \%$ of the observations in the $S$ category for 2008 come from households that always water twice and on their assigned days. Yet, the majority of customers exhibit seasonal water patterns that include a mix of different week-types and frequencies - only $18.5 \%$ of sample weeks in 2008 and $15.5 \%$ in 2010 are associated with customers that always water with the same weekly frequency. This is important for our analysis below as it suggests that the observed differences in use and peaks between SB and OS week-types are not driven by unobserved household characteristics.

Table 4 depicts weekly use and peak by frequency and week-type. We stress three key results captured by this table. First, regardless of watering pattern, consumption increases with weekly frequency. This is consistent with prior work showing that capping weekly watering frequency reduces total use. Second, peaks remain relatively stable across frequencies in the two to four applications range. Third - and most importantly - weekly consumption and peaks are substantially higher for weeks that include all assigned days ("schedule-based") compared to weeks of identical frequency with more flexible watering patterns ("off-schedule"). In 2008, these differences amount to $30-40 \%$ for weekly consumption and $50-60 \%$ for weekly peak. In 2010 these differentials are slightly attenuated amounting to $25-30 \%$ for use and $24-26 \%$ for peak. ${ }^{9}$

\footnotetext{
${ }^{8}$ We stress that our classification into different watering patterns applies to a given household-week, not a specific household across the entire research period. As discussed in the next section, the majority of households switches frequently between weekly watering patterns. Therefore, there does not exist a clear and systematic classification at the household level that distinguishes along this key dimension of decreasing schedule-adherence. However, we do control for observable and unobservable household characteristics in our econometric specification.

${ }^{9}$ The patterns captured in Tables 3 and 4 are qualitatively similar for the overlap sample. Consumption is approximately 25-35\% higher for the $S B$ group than the $O S$ group at all frequencies. Similarly, $S B$ peaks exceed $O S$ peaks by $45-55 \%$. Summary statistics for the overlap sample are available from the authors upon request.
} 
Table 3: Cell counts and percentages by watering frequency and week-type

\begin{tabular}{|c|c|c|c|c|c|c|}
\hline \multirow{2}{*}{$\begin{array}{c}\text { weekly } \\
\text { watering } \\
\text { days }\end{array}$} & \multicolumn{3}{|c|}{2008} & \multicolumn{3}{|c|}{2010} \\
\hline & count & $\begin{array}{c}\% \text { of } \\
\text { sample }\end{array}$ & $\begin{array}{c}\% \\
\text { all } \mathrm{w} / \mathrm{in}\end{array}$ & count & $\begin{array}{c}\% \text { of } \\
\text { sample }\end{array}$ & $\begin{array}{c}\% \\
\text { all } \mathrm{w} / \mathrm{in}\end{array}$ \\
\hline & \multicolumn{6}{|c|}{ schedule-based } \\
\hline $2^{*}$ & 14,497 & $27.5 \%$ & $42.8 \%$ & - & - & - \\
\hline $3^{* *}$ & 6,374 & $12.1 \%$ & $9.2 \%$ & 12,625 & $26.0 \%$ & $35.1 \%$ \\
\hline 4 & 5,595 & $10.6 \%$ & $16.1 \%$ & 3,650 & $7.5 \%$ & $3.3 \%$ \\
\hline$>4$ & 6,053 & $11.5 \%$ & $11.6 \%$ & 6,001 & $12.4 \%$ & $15.7 \%$ \\
\hline \multirow[t]{2}{*}{ Total } & 32,519 & $61.7 \%$ & $25.8 \%$ & 22,276 & $45.9 \%$ & $24.7 \%$ \\
\hline & \multicolumn{6}{|c|}{ off-schedule } \\
\hline 0 & 2,924 & $5.6 \%$ & $0.0 \%$ & 2,822 & $5.8 \%$ & $0.0 \%$ \\
\hline 1 & 4,198 & $8.0 \%$ & $1.6 \%$ & 3,979 & $8.2 \%$ & $0.9 \%$ \\
\hline 2 & 4,795 & $9.1 \%$ & $5.5 \%$ & 8,004 & $16.5 \%$ & $9.9 \%$ \\
\hline 3 & 4,257 & $8.1 \%$ & $7.4 \%$ & 6,256 & $12.9 \%$ & $8.4 \%$ \\
\hline 4 & 2,610 & $5.0 \%$ & $6.1 \%$ & 3,518 & $7.2 \%$ & $7.4 \%$ \\
\hline$>4$ & 1,363 & $2.6 \%$ & $6.5 \%$ & 1,718 & $3.5 \%$ & $2.5 \%$ \\
\hline \multirow[t]{2}{*}{ Total } & 20,147 & $38.3 \%$ & $4.4 \%$ & 26,297 & $54.1 \%$ & $6.3 \%$ \\
\hline & \multicolumn{6}{|c|}{ all } \\
\hline 0 & 2,924 & $5.6 \%$ & $0.0 \%$ & 2,822 & $5.8 \%$ & $0.0 \%$ \\
\hline 1 & 4,198 & $8.0 \%$ & $1.6 \%$ & 3,979 & $8.2 \%$ & $0.9 \%$ \\
\hline 2 & 19,292 & $36.6 \%$ & $35.5 \%$ & 8,004 & $16.5 \%$ & $9.9 \%$ \\
\hline 3 & 10,631 & $20.2 \%$ & $9.0 \%$ & 18,881 & $38.9 \%$ & $28.9 \%$ \\
\hline 4 & 8,205 & $15.6 \%$ & $13.2 \%$ & 7,168 & $14.8 \%$ & $5.4 \%$ \\
\hline$>4$ & 7,416 & $14.1 \%$ & $10.8 \%$ & 7,719 & $15.9 \%$ & $12.9 \%$ \\
\hline Total & 52,666 & $100.0 \%$ & $18.5 \%$ & 48,573 & $100.0 \%$ & $15.8 \%$ \\
\hline
\end{tabular}

\section{Econometric Framework}

To examine if these descriptive results hold up when controlling for climate variations, household characteristics, and unobserved household effects we now turn to our econometric analysis. We assume that over the course of a week a given household makes daily choices on watering occurrence and total use, given watering. From the analyst's perspective these choices will be observed as joint weekly outcomes on frequency, use, and peak. We thus define such an observed weekly irrigation scheme (IR) by household $i$ in period $p$ as a bundle of frequency $y_{1 i p}$ (zero to seven), total use $y_{2 i p}$, weekly peak $y_{3 i p}$, and schedule-based pattern $(S B$ vs. $O S)$, i.e.

$$
I R_{i p}=I R\left(y_{1 i p}, y_{2 i p}, y_{3 i p}, S B_{i p}\right), \quad i=1, \ldots N, \quad p=1 \ldots P
$$

where $S B_{i p}$ is an indicator equal to one if the weekly irrigation pattern corresponds to a schedulebased implementation, and equal to zero for an off-schedule pattern. 
Table 4: Weekly use and peak by watering frequency and week-type

\begin{tabular}{|c|c|c|c|c|c|c|c|c|}
\hline \multirow{3}{*}{$\begin{array}{c}\text { weekly } \\
\text { watering } \\
\text { days }\end{array}$} & \multicolumn{4}{|c|}{ weekly use (1000 gals.) } & \multicolumn{4}{|c|}{ weekly peak (1000 gals.) } \\
\hline & \multicolumn{2}{|c|}{2008} & \multicolumn{2}{|c|}{2010} & \multicolumn{2}{|c|}{2008} & \multicolumn{2}{|c|}{2010} \\
\hline & mean & std. & mean & std. & mean & std. & mean & std. \\
\hline & \multicolumn{4}{|c|}{ schedule-based } & \multicolumn{4}{|c|}{ schedule-based } \\
\hline 2 & 5.84 & $(3.67)$ & - & - & 2.34 & $(1.68)$ & - & - \\
\hline 3 & 6.72 & $(4.56)$ & 5.39 & $(2.44)$ & 2.30 & $(1.85)$ & 1.65 & $(0.83)$ \\
\hline 4 & 7.24 & $(5.04)$ & 5.95 & $(2.89)$ & 2.19 & $(1.86)$ & 1.67 & $(0.96)$ \\
\hline$>4$ & 9.83 & $(7.73)$ & 7.32 & $(4.41)$ & 2.43 & $(2.26)$ & 1.70 & $(1.14)$ \\
\hline Total & 6.99 & $(5.26)$ & 6.00 & $(3.26)$ & 2.32 & $(1.86)$ & 1.66 & $(0.95)$ \\
\hline & \multicolumn{4}{|c|}{ off-schedule } & \multicolumn{4}{|c|}{ off-schedule } \\
\hline 0 & 2.44 & $(2.20)$ & 2.03 & $(1.52)$ & 0.55 & $(0.48)$ & 0.46 & $(0.34)$ \\
\hline 1 & 3.38 & $(2.61)$ & 2.73 & $(1.85)$ & 1.30 & $(1.29)$ & 1.04 & $(0.94)$ \\
\hline 2 & 4.20 & $(3.20)$ & 3.82 & $(2.23)$ & 1.46 & (1.39) & 1.37 & $(0.98)$ \\
\hline 3 & 4.80 & $(3.61)$ & 4.32 & $(2.58)$ & 1.42 & $(1.28)$ & 1.31 & $(0.95)$ \\
\hline 4 & 5.52 & $(4.64)$ & 4.75 & $(3.00)$ & 1.47 & $(1.47)$ & 1.31 & $(1.04)$ \\
\hline$>4$ & 6.99 & $(5.80)$ & 5.65 & $(4.53)$ & 1.67 & (1.63) & 1.37 & $(1.24)$ \\
\hline \multirow[t]{2}{*}{ Total } & 4.26 & $(3.71)$ & 3.83 & $(2.71)$ & 1.30 & $(1.32)$ & 1.20 & $(0.99)$ \\
\hline & \multicolumn{4}{|c|}{ all } & \multicolumn{4}{|c|}{ all } \\
\hline 0 & 2.44 & $(2.20)$ & 2.03 & $(1.52)$ & 0.55 & $(0.48)$ & 0.46 & $(0.34)$ \\
\hline 1 & 3.38 & $(2.61)$ & 2.73 & $(1.85)$ & 1.30 & $(1.29)$ & 1.04 & $(0.94)$ \\
\hline 2 & 5.43 & $(3.63)$ & 3.82 & $(2.23)$ & 2.12 & $(1.65)$ & 1.37 & $(0.98)$ \\
\hline 3 & 5.95 & $(4.31)$ & 5.03 & $(2.54)$ & 1.95 & $(1.70)$ & 1.53 & $(0.89)$ \\
\hline 4 & 6.69 & $(4.98)$ & 5.36 & $(3.01)$ & 1.96 & $(1.78)$ & 1.49 & (1.01) \\
\hline$>4$ & 9.31 & $(7.50)$ & 6.95 & $(4.49)$ & 2.29 & $(2.18)$ & 1.63 & $(1.17)$ \\
\hline Total & 5.95 & $(4.91)$ & 4.82 & $(3.17)$ & 1.93 & $(1.75)$ & 1.41 & $(1.00)$ \\
\hline
\end{tabular}

Thus, we have three outcomes of interest $-y_{1 i p}, y_{2 i p}$, and $y_{3 i p}$. The first outcome, the number of watering days in a given week, takes the form of an integer that is naturally truncated from above at $U=7$. The remaining outcomes, weekly consumption and peak, are continuous with support over $\Re^{+}$. We wish to identify the effect of weekly watering frequency and degree-of-adherence to the OWR on use and peak. If household decisions on use and peak were completely independent from decisions related to weekly frequency, the three outcomes of interest could, in theory, be analyzed via independent estimation. For example, the use and peak equations could be estimated via simple random effects (RE) regression that includes difference-in-difference type interaction terms to capture the incremental effects of weekly frequency, irrigation pattern $(S B$ vs. $O S)$ and policy change (2008 vs. 2010).

However, if the frequency equation shares common unobservables with either or both of the use or peak equation, such naïve independent analysis would produce misleading results, as the righthand-side variable "frequency" would introduce endogeneity problems. We find this to indeed be 
the case in comparative estimation runs. ${ }^{10}$ Thus, a plausible econometric model for this application must accommodate the following key features: (i) Limitations on the natural range of the dependent variable, (ii) household-specific effects to control for unobserved heterogeneity, and (iii) an exante unrestricted covariance matrix for these unobserved effects, i.e. full correlation of all three equations. To incorporate these modeling challenges in a computationally tractable fashion we deviate from a standard linear regression framework and classical estimation, and turn instead to a hierarchical system approach, estimated via Bayesian tools.

As point of departure, we combine a truncated Poisson density for the watering frequency equation with two exponential densities for weekly consumption and peak (see e.g. Munkin and Trivedi, 2003). ${ }^{11}$ Adding the household effects yields our full specification, which we label the Hierarchical Truncated Poisson- Exponential (HTPE) model. The Hierarchical Truncated Poisson (HTP) component of the HTPE is given as

$$
\begin{aligned}
& f\left(y_{1 i p} \mid \lambda_{1 i p}, 0 \leq y_{1 i p} \leq U\right)=\frac{\exp \left(-\lambda_{1 i p}\right) \lambda_{1 i p}^{y_{1 i p}}}{y_{1 i p} !\left(\sum_{k=0}^{U} \frac{\lambda_{1 i p}{ }^{k}}{k !}\right)} \text { with } \\
& E\left(y_{1 i p}\right)=\lambda_{1 i p}=\exp \left(\mathbf{x}_{1 i p}^{\prime} \boldsymbol{\beta}_{1}+u_{1 i}\right)
\end{aligned}
$$

where the $\log$ of the untruncated expectation, $\lambda_{1 i p}$, is a linear function of vector $\mathbf{x}_{i p}$ containing household and climate variables, and individual-specific effect $u_{1 i}{ }^{12}$

The Hierarchical Exponential (HE) part is specified as

$$
\begin{aligned}
& f\left(y_{j i p} \mid \lambda_{j i p}\right)=\lambda_{j i p} * \exp \left(-\lambda_{j i p} y_{j i p}\right) \\
& \lambda_{j i p}=\exp \left(-\mathbf{z}_{j i p}^{\prime} \boldsymbol{\psi}_{j}-\mathbf{d}_{i p}^{\prime} \boldsymbol{\delta}_{j}-u_{j i}\right) \\
& E\left(y_{j i p}\right)=\lambda_{j i p}^{-1}=\exp \left(\mathbf{z}_{j i p}^{\prime} \boldsymbol{\psi}_{j}+\mathbf{d}_{i p}^{\prime} \boldsymbol{\delta}_{j}+u_{j i}\right), \quad j=2,3
\end{aligned}
$$

where the $\mathbf{z}$-vectors capture again household and climate information, the random terms are as in (2) and $E$ denotes the expectation operator. Importantly, vector $\mathbf{d}_{i p}$ comprises a set of $U$ indicator variables, one for each possible value of $y_{1 i p}$ that exceeds zero. The element of $\mathbf{d}_{i p}$ corresponding to the observed value of $y_{1 i p}$ is set to one, all others to zero. More concisely:

$$
d_{i p, k}=\left\{\begin{array}{ll}
1 & \text { if } y_{1 i p}=k, \\
0 & \text { otherwise }
\end{array} \quad k=1 \ldots U\right.
$$

Thus, we are allowing the intercept of the logged expectation of $y_{j i p}, j=2,3$, to shift with the observed number of watering days compared to the implicit baseline of zero outdoor watering. This implies a proportional change of $\exp \left(\mathbf{d}_{i p}^{\prime} \boldsymbol{\delta}_{j}\right)$ for the expectation in absolute terms.

\footnotetext{
${ }^{10}$ The results for these RE regressions and a discussion thereof are provided in Appendix E.

${ }^{11}$ The exponential component has similar distributional characteristics as the familiar log-normal regression model, but exhibits more desirable mixing properties in our Bayesian estimation framework.

${ }^{12}$ It should be noted that the restrictive mean-variance equality that is a prominent feature of the standard Poisson density no longer holds under truncation (e.g. Rider, 1953). A second reason for the mean-variance equality to break down is the inclusion of the random household effect. See for example Hausman et al. (1984).
} 
The model is completed by stipulating a joint density for the household effect:

$$
\mathbf{u}_{i}=\left[\begin{array}{lll}
u_{i 1} & u_{i 2} & u_{i 3}
\end{array}\right]^{\prime} \sim \operatorname{mvn}\left(\mathbf{0}, \mathbf{V}_{u}\right)
$$

where mvn denotes the multivariate normal density, and the variance matrix is ex ante unrestricted. As mentioned above, if this matrix contains non-zero covariances, a naïve model ignoring the linkage across the three equations would be plagued by endogeneity bias, since the frequency indicator $\mathbf{d}_{i p}$ appears on the right hand side of both the use and peak equation. ${ }^{13}$

Letting $\boldsymbol{\beta}_{2}=\left[\begin{array}{ll}\boldsymbol{\psi}_{2}^{\prime} & \boldsymbol{\delta}_{2}^{\prime}\end{array}\right]^{\prime}, \boldsymbol{\beta}_{3}=\left[\begin{array}{ll}\boldsymbol{\psi}_{3}^{\prime} & \boldsymbol{\delta}_{3}^{\prime}\end{array}\right]^{\prime}, \boldsymbol{\beta}=\left[\begin{array}{lll}\boldsymbol{\beta}_{1}^{\prime} & \boldsymbol{\beta}_{2}^{\prime} & \boldsymbol{\beta}_{3}^{\prime}\end{array}\right]^{\prime}$, and collecting all outcomes and explanatory data in vector $\mathbf{y}$ and matrix $\mathbf{X}$, respectively, the likelihood function for our model over all individuals $i=1 \ldots N$, unconditional on error terms, takes the following form:

$$
\begin{aligned}
& p\left(\mathbf{y} \mid \boldsymbol{\beta}, \boldsymbol{V}_{u}, \boldsymbol{X}\right)= \\
& \prod_{i=1}^{N} \int_{\mathbf{u}_{i}}\left(\prod_{p=1}^{P}\left(\frac{\lambda_{1 i p}^{y_{1 i p}}}{y_{1 i p} !\left(\sum_{k=0}^{U} \frac{\lambda_{1 i p} k}{k !}\right)} \lambda_{2 i p} \lambda_{3 i p} \exp \left(-\left(\lambda_{2 i p} y_{2 i p}+\lambda_{3 i p} y_{3 i p}\right)\right)\right)\right) \\
& f\left(\mathbf{u}_{i} \mid \mathbf{V}_{u}\right) d \mathbf{u}_{i}
\end{aligned}
$$

Given the $N$ multi-dimensional integrals over $\mathbf{u}_{i}$ this model would be challenging to estimate using conventional Maximum Likelihood procedures. We therefore employ a Bayesian estimation framework.

We begin by specifying the prior distribution for the primary model parameters, $\boldsymbol{\beta}$ and $\mathbf{V}_{u}$. We choose a standard multivariate normal prior for $\boldsymbol{\beta}$, and inverse Wishart (IW) priors for $\mathbf{V}_{u}$, i.e. $\boldsymbol{\beta} \sim \operatorname{mvn}\left(\boldsymbol{\mu}_{0}, \mathbf{V}_{0}\right), \mathbf{V}_{u} \sim I W\left(\psi_{0}, \mathbf{\Psi}_{0}\right)$. The IW parameters are the degrees of freedom and scale matrix, respectively. The IW density is parameterized such that $E\left(\mathbf{V}_{u}\right)=\left(\psi_{0}-k_{r}-1\right)^{-1} \mathbf{\Psi}_{0}$. We facilitate the implementation of our posterior simulator (Gibbs Sampler) by augmenting the model with draws of the error components $\left\{\mathbf{u}_{i}\right\}_{i=1}^{N} \cdot{ }^{14}$ The augmented posterior distribution is proportional to the priors times the augmented likelihood, i.e.

$$
\begin{aligned}
& p\left(\boldsymbol{\beta}, \mathbf{V}_{u},\left\{\mathbf{u}_{i}\right\}_{i=1}^{N}, \mid \mathbf{y}, \mathbf{X}\right) \propto \\
& p(\boldsymbol{\beta}) * p\left(\mathbf{V}_{u}\right) * p\left(\left\{\mathbf{u}_{i}\right\}_{i=1}^{N} \| \mathbf{V}_{u}\right) * p\left(\mathbf{y} \mid \boldsymbol{\beta},\left\{\mathbf{u}_{\mathbf{i}}\right\}_{i=1}^{N}, \mathbf{X}\right)
\end{aligned}
$$

where the last term describes the likelihood function conditioned on all error terms.

The Gibbs Sampler draws consecutively and repeatedly from the conditional posterior distributions $p\left(\boldsymbol{\beta} \mid\left\{\mathbf{u}_{i}\right\}_{i=1}^{N}, \mathbf{y}, \mathbf{X}\right), p\left(\mathbf{V}_{u} \mid\left\{\mathbf{u}_{i}\right\}_{i=1}^{N}\right)$,

\footnotetext{
${ }^{13}$ We also included an observation-specific error in an earlier specification. The parameter estimates generated by that model were virtually identical to those produced by the single-error specification, and both variances and covariances associated with the observational error emerged of negligible magnitude compared to the variance component for the individual-level effect.

${ }^{14}$ The data augmentation step circumvents the need to directly evaluate the integrals in (6). A general discussion of the merits of this technique of data augmentation is given in Tanner and Wong (1987). Applications with data augmentation involving hierarchical count data models include Chib et al. (1998) and Munkin and Trivedi (2003).
} 
and $p\left(\left\{\mathbf{u}_{i}\right\}_{i=1}^{N} \mid \boldsymbol{\beta}, \mathbf{V}_{u}, \mathbf{y}, \mathbf{X}\right)$. Draws of $\boldsymbol{\beta}$ and $\left\{\mathbf{u}_{i}\right\}_{i=1}^{N}$ require Metropolis - Hastings (MH) subroutines in the Gibbs Sampler. Posterior inference is based on the marginals of the joint posterior distribution. ${ }^{15}$

\section{Estimation Results}

\subsection{Posterior results}

The regressors in the parameterized expectation of the frequency equation include a combination of home characteristics and climatic variables to control for temperature and wind speed, in addition to an indicator for the 2010 irrigation season and the interaction of this indicator with the various climate variables. The parameterized mean functions for use and peak include additional home characteristics that control for indoor water use and exclude some of the climate variables for identification purpose. These equations also feature indicators for weekly watering frequency, the interaction of these terms with indicators for the 2010 watering season and schedule based weekly watering patterns, and the two-fold interaction of the schedule based and 2010 indicators with both our frequency variables and different wind measures. ${ }^{16}$

We estimate all models using the following vague but proper parameter settings for our priors: $\boldsymbol{\mu}_{0}=0, \mathbf{V}_{0}=100 * I_{k}, \psi_{0}=5$, and $\boldsymbol{\Psi}_{0}=I_{3}$. We discard the first 20,000 draws generated by the Gibbs Sampler as "burn-ins", and retain the following 10,000 draws for posterior inference. We assess convergence of the posterior simulator using Geweke's (1992) convergence diagnostics (CD). These scores clearly indicate convergence for all parameters. To gauge the degree of serial correlation in our Markov chains we also compute autocorrelation coefficients at different lags for all model parameters. These AC values drop below 0.25 by the $10^{\text {th }}$ lag for most parameters, and by the $20^{\text {th }}$ lag for all model elements. This indicates that our posterior simulator has reasonably efficient mixing properties.

The posterior results for the frequency equation are shown in Table 5. The table also captures the results for the elements of the error variance matrix $\boldsymbol{\Sigma}$, expressed as standard deviations and correlations. For each parameter we report posterior means, posterior standard deviations, and the probability mass of a given marginal posterior that lies above the zero-threshold. The effects of our various climatic controls are as expected. For example, the frequency of weekly watering events is higher on weeks with higher maximum daily temperatures and lower on weeks with higher average daily wind speeds. Interesting, however, the effect of such controls are attenuated for the 2010 season. Taken jointly, our data thus suggest that climate conditions have a more pronounced effect on the variability of watering frequency when the official OWR ceiling is lower.

Turning to the elements of $\boldsymbol{\Sigma}$ in the lower half of Table 5 , we note that with exception of $\rho_{13}$ all terms are estimated with high precision (i.e. exhibit low posterior standard deviation relative to the mean). The standard deviations (labeled $\sigma_{j}, j=1 \ldots 3$, ) are of non-negligible magnitude, which confirms the presence of unobserved household effects in all three equations. Household unobservables are highly correlated for equations two and three, and we find a mild, positive correlation between the frequency and the use equations. ${ }^{17}$

Posterior results for the weekly use and peak equations are summarized in Table 6. Regarding weekly use, the table captures three main results. First, consumption increases clearly with weekly

\footnotetext{
${ }^{15}$ The detailed steps of the posterior simulator and the Matlab code to implement this model are available from
} 
Table 5: Estimation results for frequency equation and error terms

\begin{tabular}{cccc}
\hline & mean & std. & prob $(>0)$ \\
\hline constant & -4.415 & $(0.519)$ & 0.000 \\
mintemp & -0.050 & $(0.050)$ & 0.161 \\
maxtemp & 0.151 & $(0.048)$ & 0.999 \\
avgwind & -0.988 & $(0.281)$ & 0.000 \\
maxwind & 0.407 & $(0.134)$ & 1.000 \\
gdd & 0.022 & $(0.012)$ & 0.958 \\
lnland & 0.087 & $(0.007)$ & 1.000 \\
lnvalue & 0.237 & $(0.010)$ & 1.000 \\
year2010 & 4.129 & $(0.731)$ & 1.000 \\
mintemp $* 2010$ & -0.198 & $(0.064)$ & 0.001 \\
maxtemp $* 2010$ & -0.395 & $(0.086)$ & 0.000 \\
avgwind $* 2010$ & 0.760 & $(0.295)$ & 0.997 \\
maxwind ${ }^{*} 2010$ & -0.281 & $(0.139)$ & 0.019 \\
gdd * 2010 & 0.061 & $(0.019)$ & 0.999 \\
& & & \\
std.'s and corr.'s for $\mathbf{u}_{i}$ & & & \\
$\sigma_{1}$ & 0.434 & 0.004 & 1.000 \\
$\rho_{12}$ & 0.056 & 0.014 & 1.000 \\
$\sigma_{2}$ & 0.477 & 0.005 & 1.000 \\
$\rho_{13}$ & -0.005 & 0.014 & 0.364 \\
$\rho_{23}$ & 0.985 & 0.001 & 1.000 \\
$\sigma_{3}$ & 0.527 & 0.005 & 1.000 \\
\hline mean $=$ posterior mean, & & & \\
ptd. $=$ posterior standard deviation,$~$ & & \\
\hline 0$)$ share of posterior density to the right of zero & & &
\end{tabular}

frequency. Furthermore, this result remains essentially unchanged in 2010. Second, weeks associated with schedule-based $(S B)$ watering exhibit increased use compared to the implicit off-schedule $(O S)$ baseline at any frequency. These rigidity penalties amount to 20-23 percent, and are highest for weeks that follow the official schedule exactly. ${ }^{18}$ Third, controlling for frequency and watering pattern, the residual policy effect is of negligible magnitude.

The results for weekly peak are given in the last three columns of the table. In contrast to use, peaks do not change much over frequency in either year. However, as for use, peaks are substantially larger for $S B$-type weeks compared to $O S$-type patterns in 2008, and this difference is greater at lower frequency levels. This gap diminishes in 2010, as peaks for $S B$-type implementations decrease by 18-23 percent compared to the 2008 season, and peaks for $O S$-types increase slightly (by 6-9 percent). The reduction in the "rigidity penalty" for peaks in 2010 compared to 2008 likely reflects

the authors upon request.

${ }^{16}$ Details on household and climate regressors are provided in Appendix D.

${ }^{17}$ As illustrated in the Appendix E, this linkage via unobservables between equations one and two is sufficient to produce inconsistent parameter estimates for both use and peak models if the system is estimated via independent random effects regressions.

${ }^{18}$ We use the conversion formula of $\exp (\beta)-1$ suggested by Halvorsen and Palmquist (1980) to interpret marginal effects associated with binary variables, given the log-normal form of the parameterized mean function. 
the additional flexibility afforded to compliant customers by the revised OWRs. Schedule-adherent households now have more options to reduce daily watering on windy days and are less likely to face the dilemma of incurring wind losses or violating official rules by making up for a skipped application on non-assigned days.

However, we also acknowledge that to some extent this reduction in rigidity gap, especially via increased peaks for $O S$-types, might be an artifact of our classification scheme: Some 2010 customers may have been sluggish to adjust to the new schedule. As a result, the "rigid" weeks produced by these residents, classified as $S B$ in 2008, are counted as $O S$-types in $2010 .{ }^{19}$ As such, our estimates can be interpreted an upper bound on the effect of the policy change on the rigidity penalty for peak use.

The remaining findings for the peak model mirror those from the weekly use equation: namely, there are no noteworthy residual policy effects. Overall, we conclude that the results produced by our complete econometric specification support the descriptive findings from the preceding section.

Table 6: Estimation results for use and peak equations

\begin{tabular}{|c|c|c|c|c|c|c|}
\hline & \multicolumn{3}{|c|}{ weekly use } & \multicolumn{3}{|c|}{ weekly peak } \\
\hline & mean & std. & $\operatorname{prob}(>0)$ & mean & std. & $\operatorname{prob}(>0)$ \\
\hline constant & -10.766 & $(0.773)$ & 0.000 & -12.706 & $(0.766)$ & 0.000 \\
\hline freq1 & 0.392 & $(0.025)$ & 1.000 & 0.883 & $(0.026)$ & 1.000 \\
\hline freq2 & 0.584 & $(0.025)$ & 1.000 & 0.980 & $(0.026)$ & 1.000 \\
\hline freq3 & 0.720 & $(0.026)$ & 1.000 & 0.989 & $(0.027)$ & 1.000 \\
\hline freq4 & 0.821 & $(0.029)$ & 1.000 & 0.992 & $(0.031)$ & 1.000 \\
\hline freq 567 & 0.967 & $(0.036)$ & 1.000 & 1.048 & $(0.036)$ & 1.000 \\
\hline $\mathrm{SB} *$ freq 2 & 0.208 & $(0.066)$ & 1.000 & 0.379 & $(0.068)$ & 1.000 \\
\hline $\mathrm{SB} *$ freq 3 & 0.197 & $(0.066)$ & 0.999 & 0.334 & $(0.068)$ & 1.000 \\
\hline $\mathrm{SB} *$ freq 4 & 0.179 & $(0.068)$ & 0.995 & 0.307 & $(0.071)$ & 1.000 \\
\hline $\mathrm{SB} *$ freq 567 & 0.200 & $(0.071)$ & 0.999 & 0.233 & $(0.072)$ & 0.999 \\
\hline year2010 & 0.185 & $(0.740)$ & 0.593 & -0.178 & $(0.730)$ & 0.403 \\
\hline freq1 $* 2010$ & -0.010 & $(0.036)$ & 0.393 & -0.009 & $(0.036)$ & 0.385 \\
\hline freq $2 * 2010$ & 0.034 & $(0.035)$ & 0.837 & 0.073 & $(0.035)$ & 0.978 \\
\hline freq $3 * 2010$ & 0.045 & $(0.036)$ & 0.895 & 0.071 & $(0.036)$ & 0.977 \\
\hline freq $4 * 2010$ & 0.053 & $(0.041)$ & 0.901 & 0.092 & $(0.041)$ & 0.990 \\
\hline freq5 $567 * 2010$ & 0.038 & $(0.049)$ & 0.786 & 0.064 & $(0.048)$ & 0.909 \\
\hline $\mathrm{SB} *$ freq $3 * 2010$ & -0.052 & $(0.144)$ & 0.361 & -0.257 & $(0.147)$ & 0.039 \\
\hline $\mathrm{SB} *$ freq $4 * 2010$ & -0.049 & $(0.146)$ & 0.357 & -0.244 & $(0.150)$ & 0.049 \\
\hline $\mathrm{SB} *$ freq $567 * 2010$ & -0.041 & $(0.147)$ & 0.395 & -0.200 & $(0.151)$ & 0.088 \\
\hline
\end{tabular}

(results for household and climate variables are omitted for brevity, but are given in Appendix D)

mean $=$ posterior mean,

std. = posterior standard deviation,

$\operatorname{prob}(>0)=$ share of posterior density to the right of zero

\footnotetext{
${ }^{19}$ Recall that every $S B$ designated week must include outdoor use on all assigned days. Hence, any 2008 scheduleadherent household who fails to adjust to the new OWRs by watering on the third allowable day and switching to the new assigned week-days during 2010 would produce $O S$-type weeks for that year - even if there was no change in the actual watering pattern relative to the 2008 season.
} 


\subsection{Predictive analysis}

For a more direct comparison of weekly consumption and peak across weeks with different watering patterns we generate posterior predictive densities (PPDs) for each irrigation type ( $B$ vs. $O S$ ). Formally, these PPDs are given as

$$
\begin{aligned}
& p\left(y_{j} \mid \mathbf{x}_{\mathrm{tf}}\right)= \\
& \left.\int_{\boldsymbol{\theta}}\left(\int_{u_{i j}}\left(\left(y_{j} \mid \mathbf{x}_{\mathrm{tf}}, \boldsymbol{\beta}, u_{j i}\right) f\left(u_{j i} \mid \mathbf{V}_{u}\right)\right) d u_{i j}\right)\right) p(\boldsymbol{\theta} \mid \mathbf{y}, \mathbf{X}) d \boldsymbol{\theta} \\
& j=2,3
\end{aligned}
$$

where $\mathbf{x}_{\mathrm{tf}}$ denotes a specific combination of watering pattern $\mathrm{t} \in\{S B, O S\}$ and frequency $\mathrm{f} \in$ $\{2,3,4\}$, and vector $\boldsymbol{\theta}$ comprises the entire set of model parameters. In practice, we simulate these PPDs by (i) drawing 10 random coefficients from $f\left(u_{j i} \mid \mathbf{V}_{u}\right)$ ), (ii) computing $\lambda_{i j}$ for each $u_{i j}$ as given in (2), and (iii) drawing $y_{j}$ from the exponential density with expectation $\lambda_{i j}$. We repeat steps (ii) and (iii) for all 10 draws of $u_{i j}$, and steps (i) through (iv) for all 10,000 draws of $\boldsymbol{\theta}$ from the original Gibbs Sampler.

Except for the combination $\mathrm{t}=S B, \mathrm{f}=2$, which is only meaningful for 2008 , we derive separate PPDs for $y_{j} \mid \mathbf{x}_{\mathrm{tf}}$ for 2008 and 2010 by setting the 2010 indicator and interaction terms accordingly in the covariate matrix for the use and peak equations. We combine these year-specific PPDs for final analysis as there is discernible difference in watering behavior across these years once we control for climatic and household specific variables. The latter are set to their grand sample means for this predictive analysis.

The resulting PPDs are depicted in Figure 1 for use and Figure 2 for peak. Each subplot shows PPDs for $S B$ and $O S$ types for a given frequency. Posterior predictive expectations are superimposed as vertical lines and labeled with their respective numerical value (in 1000 gallons). As is evident from Figure 1, the $S B$ pattern produces higher expected use than the $O S$ pattern at all frequencies, with a slightly decreasing relative gap from 14 percent at $\mathrm{f}=2$ to 12 percent at $\mathrm{f}=4$. As shown in Figure 2 these differences in posterior predictive expectation are even more pronounced for peak. At two watering days, the $S B$ pattern generates a peak that is approximately 28 percent higher than the $O S$ peak. At three watering days, this difference reduces to 22 percent, and at a frequency of four it amounts to close to 18 percent. Overall, these predictive results support our descriptive and analytical findings - a watering pattern that closely follows the officially assigned days produces noticeably higher weekly consumption and substantially higher peaks than a more flexible distribution of the same number of watering days across a given week.

\section{The Wind Effect}

As mentioned at the onset, we believe that the assignment of household-weeks into different watering patterns is largely driven by exogenous shocks in the form of high wind events. Specifically, some customers switch to more flexible irrigation patterns to avoid wind-induced water losses. Conversely, households that follow the assigned schedule are more likely to water under adverse natural conditions such as high wind events. This increases both use and peak, as it takes more water per week and per daily application to provide adequate irrigation for a given landscape. 

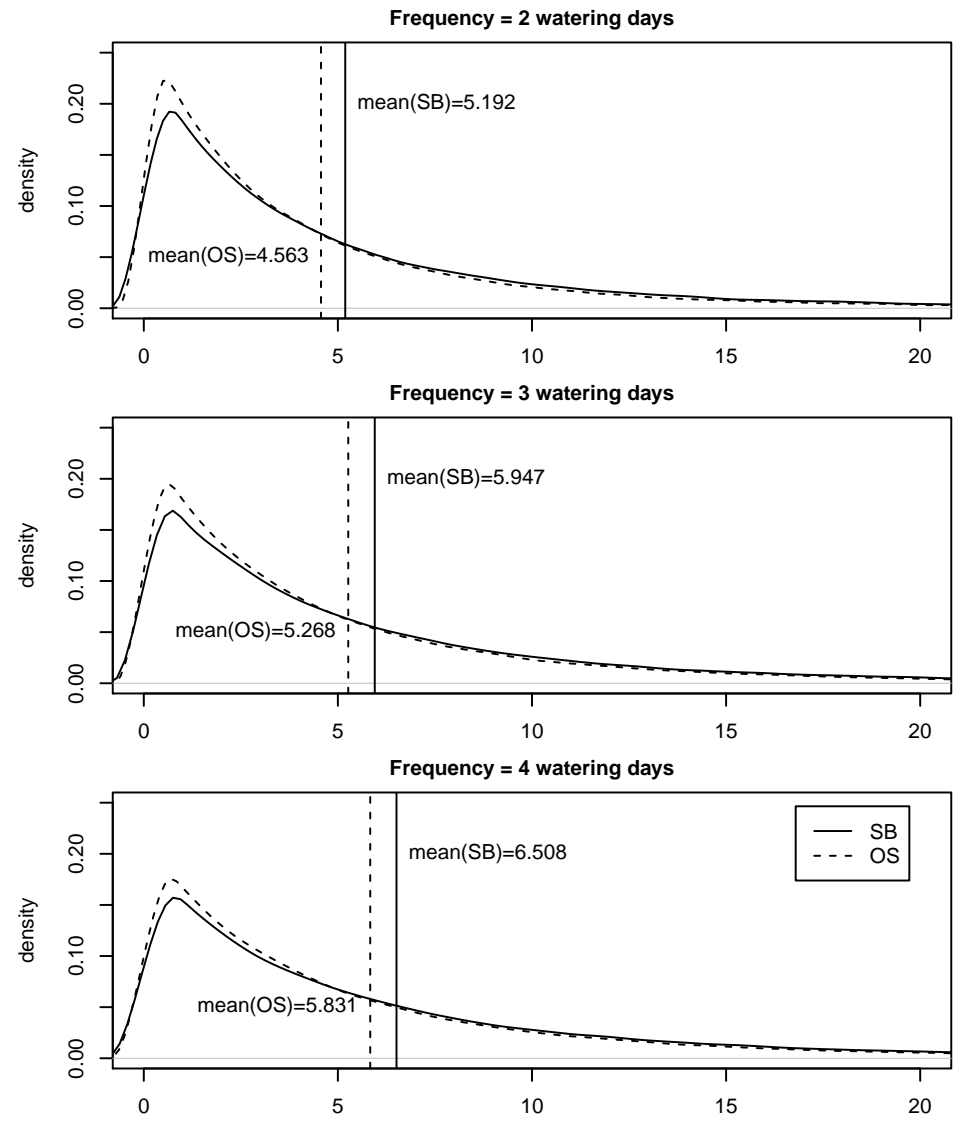

Figure 1: Predictive distributions of weekly use for a typical household (1000 gallons)

To explore this conjecture in greater detail, we compute the percentage of watering days that fall on either a windy or very windy day. ${ }^{20}$ The results are captured in Table 7 . In 2008 the average watering day had a $51 \%$ chance of occurring on a windy day and an $18 \%$ chance of coinciding with a very windy day. Importantly, these percentages are higher for the $S B$ group compared to the $O S$ segment at essentially all frequencies. In 2008, this difference is especially pronounced for the $S$ category - the share of windy days exceeds the correponding value for $O S$ / twice a week by over $6 \%$. In general, $S B$ type weeks were $3-6 \%$ more likely to occur on a windy day and $2-3 \%$ more likely to fall on a very windy day than $O S$ type weeks of comparable frequency. In 2010, which had slightly fewer windy days overall compared to 2008, the difference in the relative frequency of wind events across week-types reduces to 1-2\% for windy days and falls below the $1 \%$ mark for very windy days. However, as for 2008, the $S$ category experiences the highest risk of wind exposure.

To provide more rigorous support for this "wind hypothesis" we estimate a Probit models of daily watering decision on average daily temperature (F), an indicator for "windy day" (with max. sustained speed exceeding the sample mean of 16 knots), an interaction term for "windy" and "SB",

20 "Windy days" are those with a maximum sustained wind speed that exceeds the sample mean (16.51 knots). "Very windy" days are defined as those with a maximum sustained wind speed at the 75 th percentile (19 knots) or higher. 

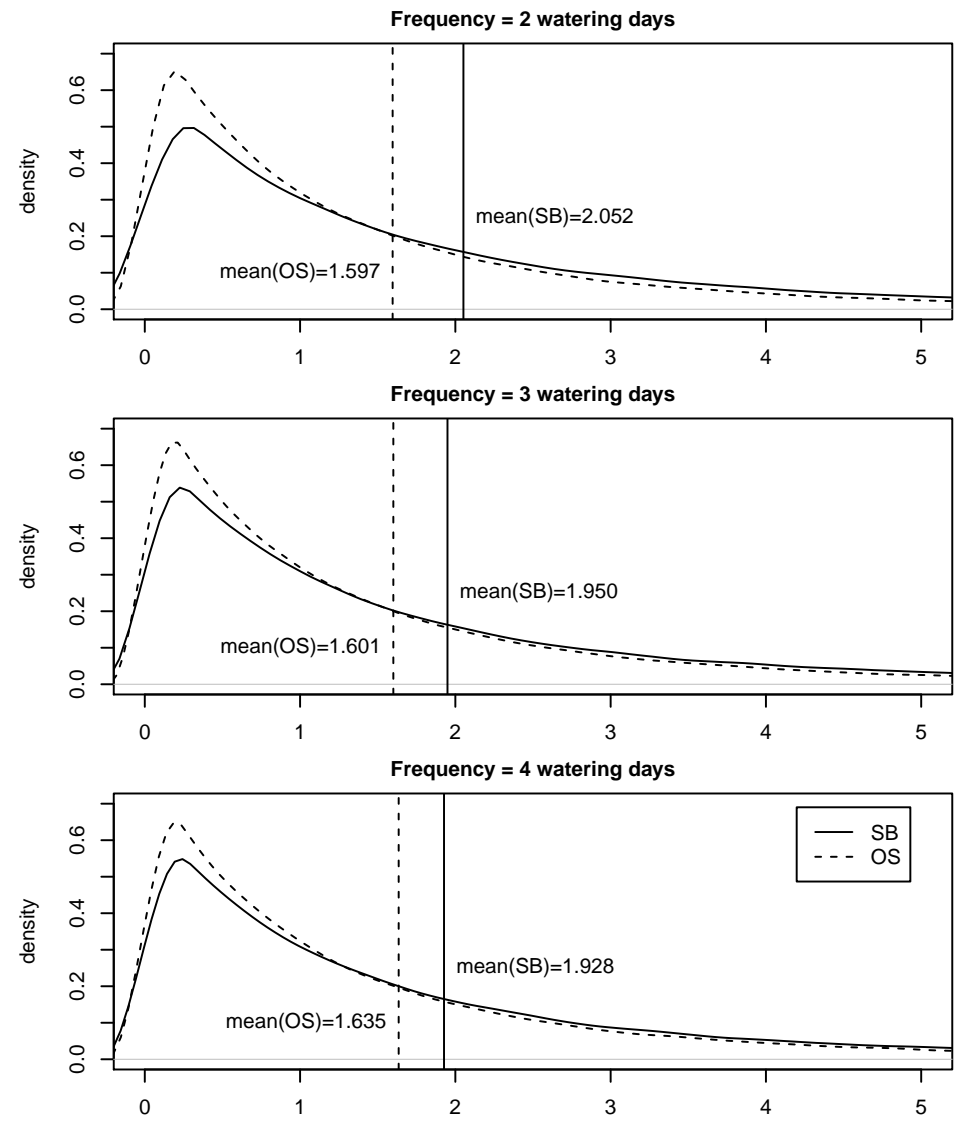

Figure 2: Predictive distributions of weekly peak for a typical household (1000 gallons)

and a random household effect. We estimate separate models for the two sample years, and weekly frequencies of 2,3 , and 4 watering days.

The results are captured in Table 8. For ease of interpretation, the estimated coefficients are presented as marginal effects, conditional on a random effect of zero. As can be seen from the table, in 2008 the probability of a observed watering day to coincide with above-average wind conditions is approximately $5 \%$ higher for an "SB" type HW compared to an "OS" type. This difference shrinks to $1-3 \%$ in 2010, but is still significant. Thus, the Probit estimates pair up well with our descriptive insights in supporting the conjecture that wind events may well be the main driver of the observed variability in weekly watering patterns, and associated differences in use and peaks across irrigation types. ${ }^{21}$

\footnotetext{
${ }^{21}$ Irrigation losses due to wind can easily amount to $40-50 \%$ in arid climates, even under moderate wind speeds of $10 \mathrm{mph}$ (8-9 knots) or less (Bauder, 2000; Duble, 2013). Naturally, these losses are further exacerbated if even the water that hits the ground completely misses its target, which is a common occurrence for the relatively small yards in our research area.
} 
Table 7: Wind events by watering frequency and week type

\begin{tabular}{|c|c|c|c|c|c|c|}
\hline \multirow{2}{*}{$\begin{array}{c}\text { weekly } \\
\text { watering } \\
\text { days }\end{array}$} & \multicolumn{2}{|c|}{2008} & \multicolumn{2}{|c|}{2010} & \multicolumn{2}{|c|}{ All } \\
\hline & $\begin{array}{c}\% \\
\text { windy }\end{array}$ & $\begin{array}{c}\% \\
\text { very windy }\end{array}$ & $\begin{array}{c}\% \\
\text { windy }\end{array}$ & $\begin{array}{c}\% \\
\text { very windy }\end{array}$ & $\begin{array}{c}\% \\
\text { windy }\end{array}$ & $\begin{array}{c}\% \\
\text { very windy }\end{array}$ \\
\hline & \multicolumn{6}{|c|}{ schedule-based } \\
\hline 2 & $57.02 \%$ & $21.40 \%$ & - & - & $57.02 \%$ & $21.40 \%$ \\
\hline 3 & $52.32 \%$ & $19.50 \%$ & $48.82 \%$ & $18.09 \%$ & $50.00 \%$ & $18.57 \%$ \\
\hline 4 & $52.21 \%$ & $19.37 \%$ & $48.58 \%$ & $17.66 \%$ & $50.78 \%$ & $18.69 \%$ \\
\hline$>4$ & $46.75 \%$ & $15.29 \%$ & $47.09 \%$ & $17.34 \%$ & $46.92 \%$ & $16.32 \%$ \\
\hline \multirow[t]{2}{*}{ Total } & $51.71 \%$ & $18.58 \%$ & $48.08 \%$ & $17.72 \%$ & $50.06 \%$ & $18.19 \%$ \\
\hline & \multicolumn{6}{|c|}{ off-schedule } \\
\hline 2 & $50.68 \%$ & $19.08 \%$ & $47.73 \%$ & $18.38 \%$ & $48.83 \%$ & $18.65 \%$ \\
\hline 3 & $48.65 \%$ & $16.60 \%$ & $46.94 \%$ & $17.67 \%$ & $47.63 \%$ & $17.24 \%$ \\
\hline 4 & $49.51 \%$ & $17.18 \%$ & $46.99 \%$ & $17.25 \%$ & $48.07 \%$ & $17.22 \%$ \\
\hline$>4$ & $47.40 \%$ & $15.14 \%$ & $46.58 \%$ & $16.42 \%$ & $46.94 \%$ & $15.85 \%$ \\
\hline \multirow[t]{2}{*}{ Total } & $49.14 \%$ & $17.09 \%$ & $47.11 \%$ & $17.57 \%$ & $47.94 \%$ & $17.37 \%$ \\
\hline & \multicolumn{6}{|c|}{ all } \\
\hline 2 & $55.44 \%$ & $20.82 \%$ & $47.73 \%$ & $18.38 \%$ & $53.18 \%$ & $20.11 \%$ \\
\hline 3 & $50.85 \%$ & $18.34 \%$ & $48.20 \%$ & $17.95 \%$ & $49.15 \%$ & $18.09 \%$ \\
\hline 4 & $51.35 \%$ & $18.67 \%$ & $47.80 \%$ & $17.46 \%$ & $49.70 \%$ & $18.11 \%$ \\
\hline$>4$ & $46.86 \%$ & $15.27 \%$ & $46.99 \%$ & $17.16 \%$ & $46.93 \%$ & $16.23 \%$ \\
\hline Total & $51.00 \%$ & $18.17 \%$ & $47.70 \%$ & $17.66 \%$ & $49.35 \%$ & $17.91 \%$ \\
\hline
\end{tabular}

\section{Conclusion}

This study is the first to examine how the design of outdoor watering restrictions impacts residential water use at the household level. Using a unique, customer specific data set of daily consumption over multiple irrigation seasons that include an inter-season policy change, we arrive at several important and novel findings. Most centrally, both the cap on weekly frequency and the address-based assignment of specific watering days matter for conservation outcomes. While the former is confirmed to be necessary for curbing consumption, the latter undermines conservation goals.

We find that higher frequencies unambiguously translate into higher weekly use. However, we uncover an unintended consequence of OWRs with days-of-week assignments: weekly use and peak are higher the more closely a given households follows the assigned schedule. These "rigidity penalties" are substantial and amount to approximately 20-25 percent of weekly consumption and 30-40 percent of weekly peaks.

The policy change from two to three assigned days per week produced two main effects. First, it induced the intended switch in watering patterns for a considerable segment of customer-weeks. Second, we observe a pronounced reduction in peaks at the system-wide level - an effect driven predominantly by lower peaks for schedule-based weeks. In contrast, overall weekly use changes little in reaction to the new policy. 
Table 8: Random Effects Probit Estimation of Daily Watering Decision (translated into Marginal Effects)

\begin{tabular}{|c|c|c|c|c|c|c|c|}
\hline \multicolumn{4}{|c|}{2008} & \multicolumn{4}{|c|}{2010} \\
\hline \multirow{5}{*}{$\begin{array}{c}\text { windy } \\
\text { windy*SB } \\
\text { avg. temp. }\end{array}$} & \multicolumn{3}{|c|}{ weekly frequ. $=2(\mathrm{n}=135,044)$} & & & & \\
\hline & coeff. & s.e. & $\mathrm{z}$ & & & & \\
\hline & 0.074 & 0.004 & 17.870 & & & & \\
\hline & 0.049 & 0.004 & 12.070 & & & & \\
\hline & 0.011 & 0.000 & 25.190 & & & & \\
\hline \multicolumn{4}{|c|}{ weekly frequ. $=3(\mathrm{n}=74,417)$} & \multicolumn{4}{|c|}{ weekly frequ. $=3(\mathrm{n}=132,167)$} \\
\hline & coeff. & s.e. & $\mathrm{z}$ & & coeff. & s.e. & $\mathrm{z}$ \\
\hline windy & 0.033 & 0.005 & 6.290 & windy & 0.003 & 0.004 & 0.670 \\
\hline windy*SB & 0.053 & 0.005 & 9.900 & windy*SB & 0.013 & 0.004 & 3.030 \\
\hline avg. temp. & 0.005 & 0.001 & 8.380 & avg. temp. & 0.001 & 0.000 & 2.730 \\
\hline \multicolumn{4}{|c|}{ weekly frequ. $=4(\mathrm{n}=57,435)$} & \multicolumn{4}{|c|}{ weekly frequ. $=4(\mathrm{n}=50,176)$} \\
\hline & coeff. & s.e. & $\mathrm{z}$ & & coeff. & s.e. & $\mathrm{z}$ \\
\hline windy & 0.055 & 0.006 & 8.510 & windy & 0.000 & 0.006 & 0.070 \\
\hline windy*SB & 0.053 & 0.006 & 8.430 & windy*SB & 0.016 & 0.006 & 2.470 \\
\hline avg. temp. & 0.009 & 0.001 & 12.310 & avg. temp. & 0.001 & 0.000 & 1.450 \\
\hline
\end{tabular}

For policy-makers, our results suggest that adjusting existing OWRs to allow for flexible watering patterns could produce substantial water savings at relatively low implementation costs. Moreover, as inefficiency penalties are highest at low frequencies, our findings also cast doubt on the effectiveness of policies that reduce the number of assigned days under progressively severe drought conditions. In such situations, a frequency reduction combined with a "free-to-choose" policy is likely to promote greater conservation. Naturally, violations of allowed weekly frequencies would be more difficult to detect under such a policy, since permissible applications would no longer be pegged to a given day-of-week for a given address. However, the fact that many current customers adhere - at least loosely - to the official regulations despite weak enforcement by the utility suggests that social norms and "neighborly supervision" may be stronger drivers of compliance than officially posted fines. These norms would still be in force under more flexible policies, as nearby neighbors can easily keep track of other households' weekly watering frequency.

Our analysis extends prior work exploring the unintended consequences of nested policies, and those that introduce heterogeneous standards across firms and/or regions. Whereas the extant literature focuses on leakages generated by the spatial reallocation of effort, our paper highlights another channel through which leakages may arise - by hampering the temporal reallocation of effort. In our setting, adherence to the official watering schedule requires households to ignore time-varying weather patterns that reduce the efficacy of outdoor watering.

It is easy to envision other domains where similar patterns could arise. For example, many utilities have explored time-of-day pricing as a means to manage residential energy consumption and associated greenhouse gas emissions. To the extent that such pricing schemes cause a shift in demand from peak to non-peak hours, the overall impact on carbon could fall short of expectations as the marginal fuel source during peak hours is often less carbon intensive than base load generators (the marginal fuel source during non-peak periods). The identification of such temporal leakages and the design of policies that are robust to such unintended consequences should provide ample 
opportunities for future research. 
Appendix A. Outdoor watering restrictions in the United States 


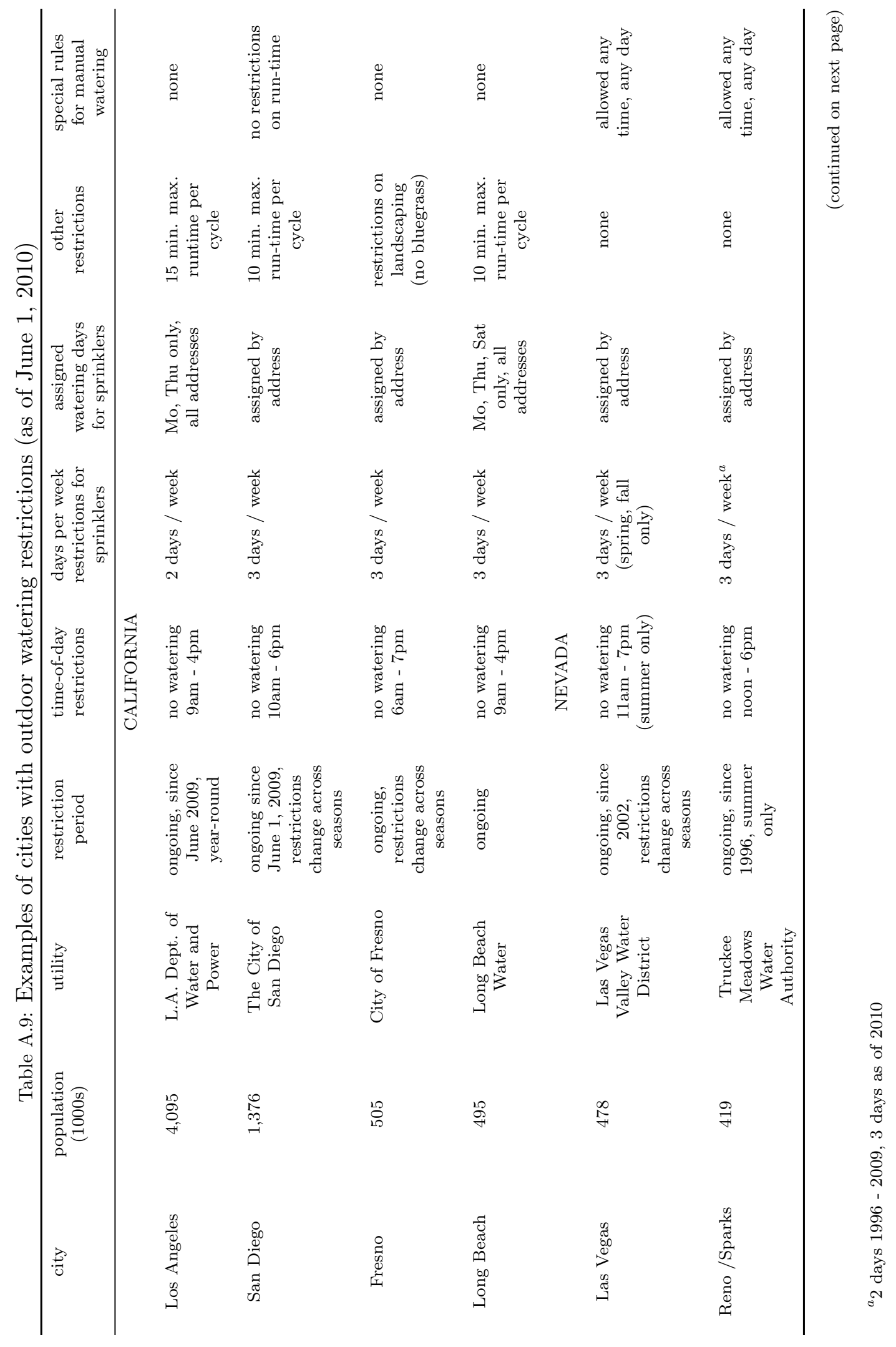




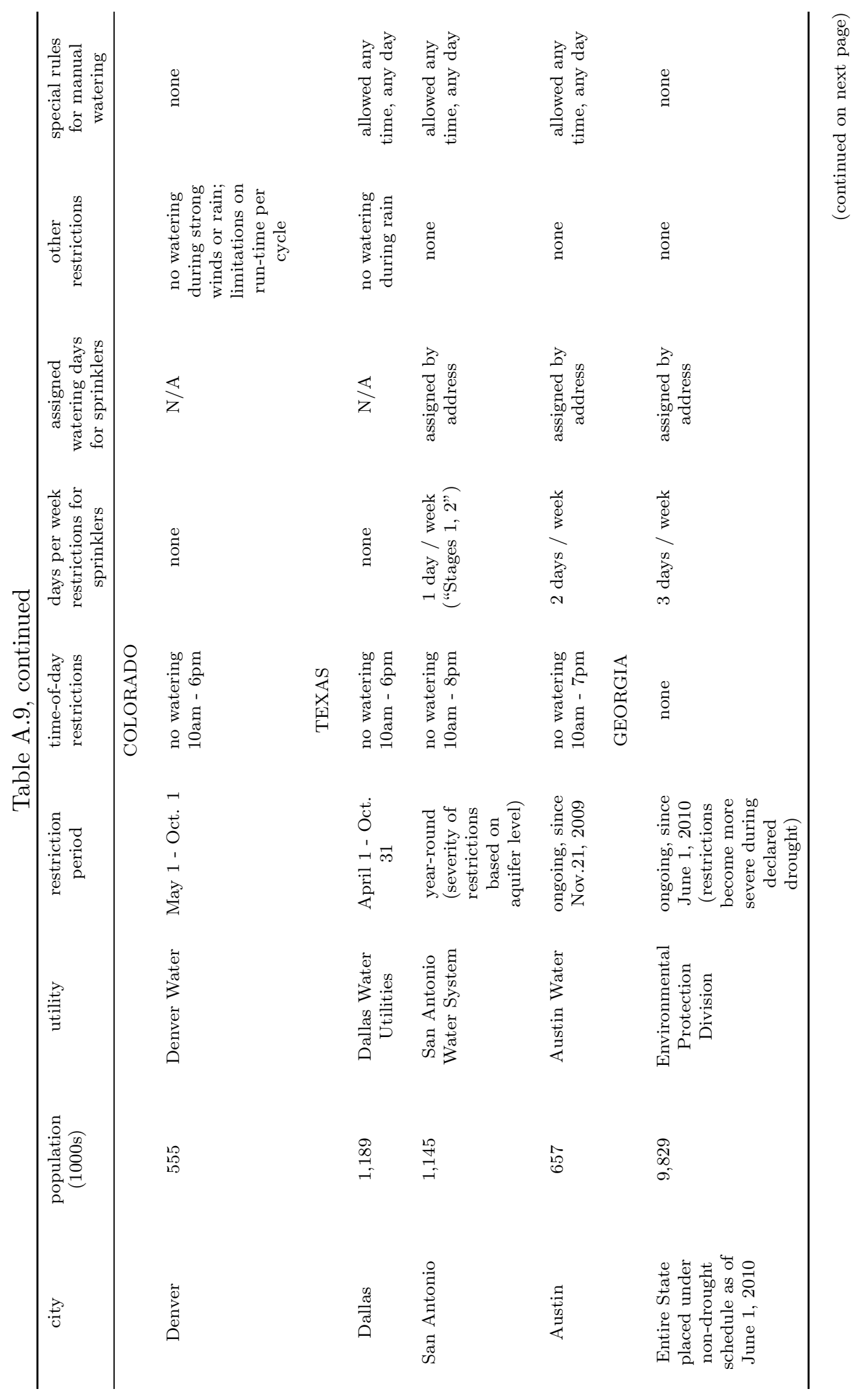




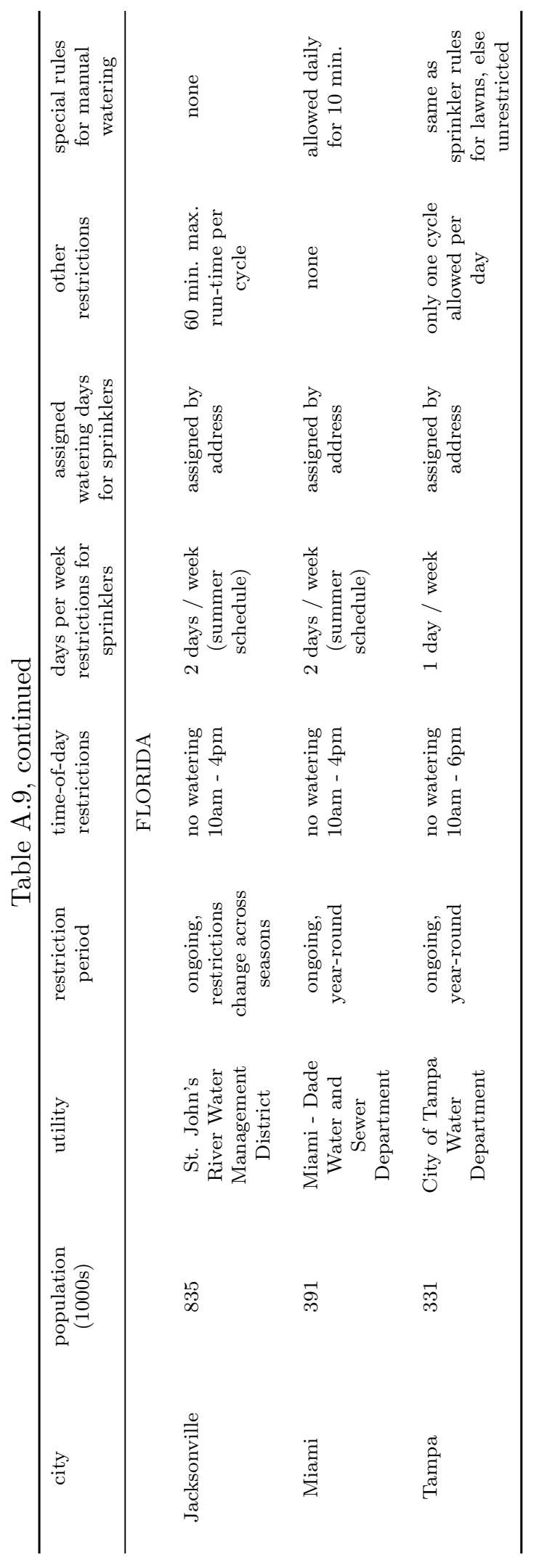




\section{Appendix B. Evidence against confounding effects}

If there were any other time-varying factors that drive water need in a heterogeneous fashion we should see pronounced variation over time in the fraction of different watering types. Table B.10 shows, for each week of our research period, the number of households included in the sample, and the percentage of watering types. The last two columns of the table capture the two types we use in our empirical model, $S B$ and $O S$. For additional insight, we also show the percentage, of the total sample, of perfectly compliant types, or $S$ types (which are nested within $S B$ ). We further split these $S$ types into the percentage of household-weeks (HWs) that come from households that always follow the schedule (labeled as "always" in the table), and the remaining share of HWs contributed by "occasional" perfect compliers (labeled as "occ") in the table.

Table B.10: Percentages of watering types over time

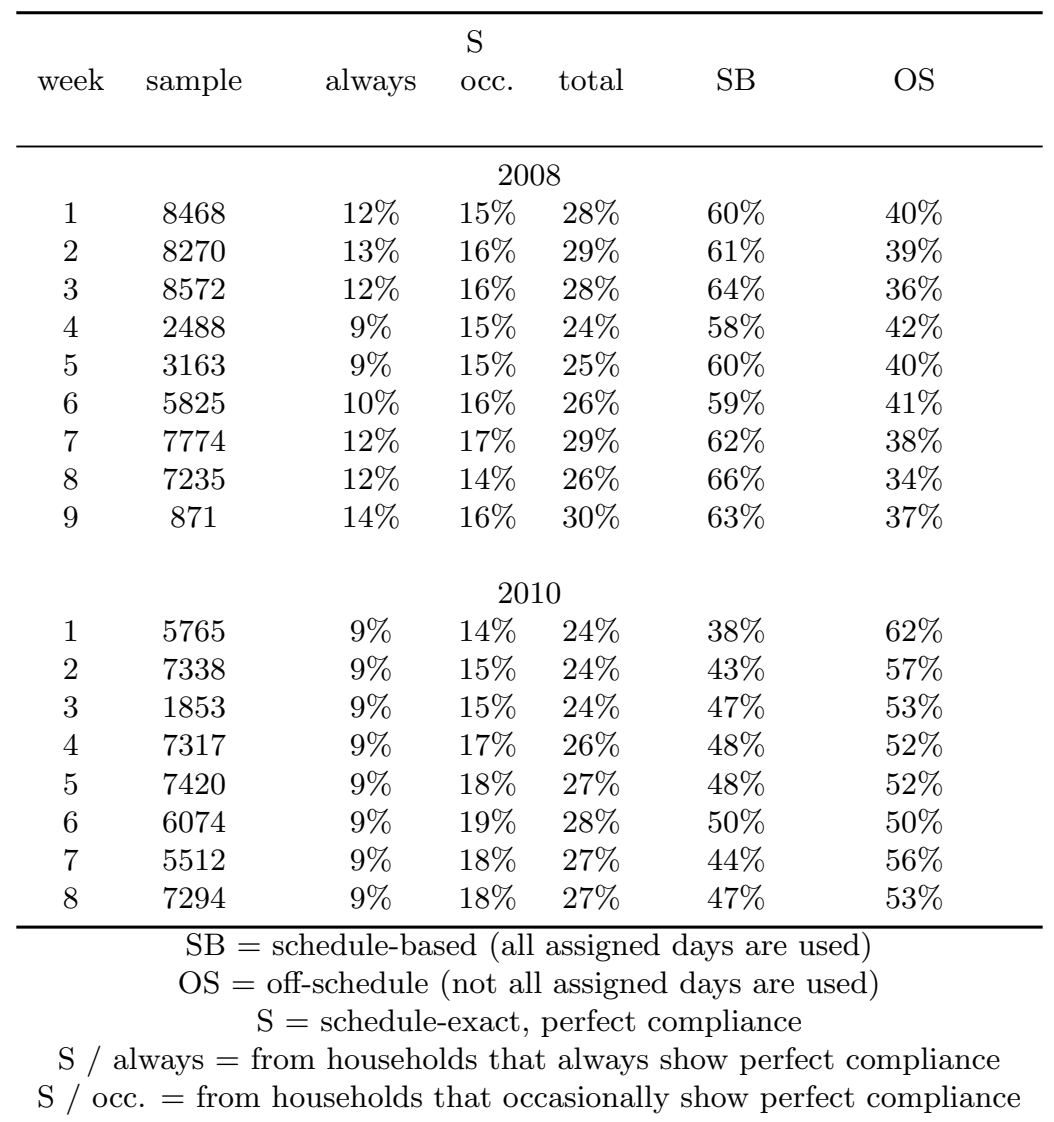

As can be seen from the table, there are no pronounced shifts in the proportion of type assignments over time. This puts in question the proposition that a substantial share of $O S$ types become $S B$ types due to a systematic weekly shock that affects water need. Table 2 in the main text and table B.10 combined also show that the hottest weeks in 2008 (week 3) and 2010 (week 4 ) do not produce the highest proportion of $S$ or $S B$ types in the overall watering pattern.

It is also obvious from B.10 that perfectly compliant HWs, or $S$ types constitute the minority of $S B$ types in any given week. Most HWs that are $S B$ have a watering pattern that adds one or more 
days to the official schedule. In other words, they are already cheating to some extent. Throughout our analysis we compare $S B$ types and $O S$ types conditional on the same weekly frequency. This means that an $O S$ type cheats just slightly more than an $S B$ type of the same frequency. Therefore, the probability of detection and fines should not be all that different between the two types.

Furthermore, if the "behave to avoid fines when water needs are high" conjecture were to hold, we would expect to see higher use for $S$ types compared to one-off $S B$ types. For example, in 2008, an $S$ type would water exactly twice. We can then compare the resulting weekly use to that of an $S B-3$ type that uses one additional day. In the same vein, we can compare an $S$ type for 2010 (3 allowable watering days) to an $S B-4$ type. In both cases we would expect use to increase under the $S$ regime under the conjecture.

However, as is evident from Figure B.3, the one-off $S B$ types use more water than perfect compliers and have comparable peaks to $S$ types in both years. This picture is more consistent with the notion that when a households needs more water, it simply adds an additional day. This directly contradicts the "revert to $S$ when need is high" hypothesis.

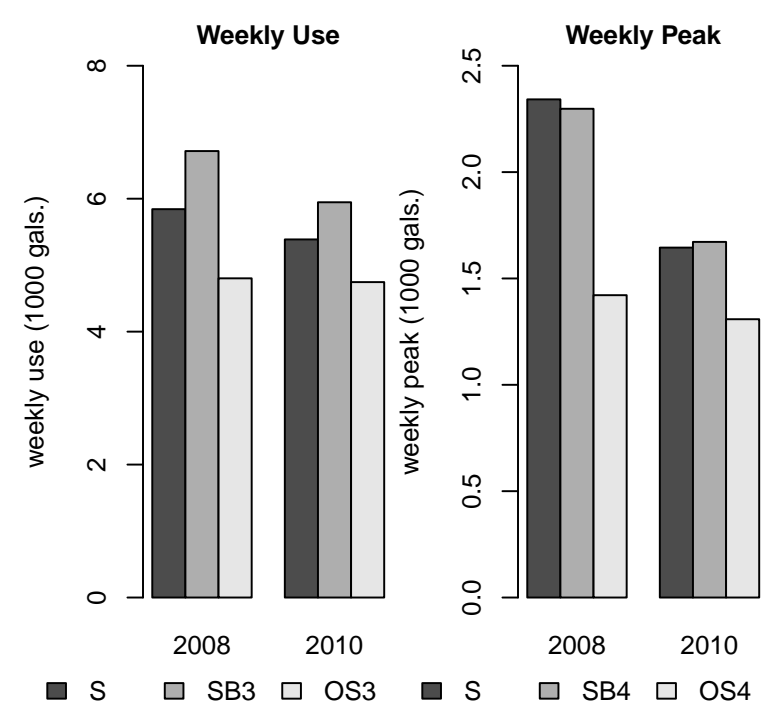

Figure B.3: Weekly Use and Peak for $S$ and "one-off" Types 


\section{Appendix C. Identification of outdoor watering days}

Our identification of outdoor watering days thus proceeds in the following steps:

1. We start with a simple $K$-means clustering algorithm (MacQueen, 1967) at the household level to classify each day as a "high use" or "low use" occurrence. Our objective is to confidently interpret high use days as days with outdoor irrigation, and low-use days as days with strictly non-irrigation consumption. We use six different clustering algorithms. The first three are based on actual daily use, the second set of three on logged use. ${ }^{22}$ Within each set, the first algorithm uses the Euclidean distance between observation points and the current pair of cluster centroids as a sorting criterion, the second uses Euclidean distance squared, and the third absolute distance (Vinod, 1969; Massart et al., 1983). In each case we use the mean consumption on assigned and unassigned days, respectively, as starting values for the cluster centroids.

We find that within each triplet all three algorithms agree on sorting for every single observation in both the 2008 and 2010 data sets. This indicates robustness to the choice of similarity measure, which is reassuring. As expected, the versions based on logged use, which are less sensitive to outliers and thus lower the threshold for observations to fall into the higher category, identify about 10-15 percent more observations as watering days than the versions based on actual use in gallons in each data set.

However, all six versions are in complete agreement for all daily observations associated with 1644 (18.8 percent) of households in 2008, and 890 households (11.7 percent) in 2010. These are likely customers that exclusively water via automated sprinkler systems, producing very pronounced differences in usage between irrigation and non-irrigation days. Within these subgroups, the sorting into watering and non-watering days perfectly aligns with assigned watering days for 604 (6.9 percent) of customers in 2008, and 422 (5.5 percent) of customers in 2010. For these households we can be especially confident that the observations flagged as non-watering days truly and exclusively capture indoor, or non-irrigation, use. In the following, we label these households as "Full Agreement, Full Compliance" (FAFC) cases.

An inspection of sample statistics on basic building and lot characteristics assures us that these FAFC cases are not systematically different in measurable ways from the remainder of the data set. ${ }^{23}$ Thus, we deem them suitable as a representative sub-sample that provides reliable and important information on non-irrigation use.

2. Our next goal is to utilize information on winter use and the fact that the Reno / Sparks climate precludes any water use for outdoor irrigation during the cold season to validate the cluster analysis results. Specifically, using available data on monthly consumption during the January-March period preceding our summer data collections, we compute average daily winter use and the ratio of daily summer use to average daily winter use for each household in both data sets. Focusing again on the FAFC observations, we then inspect the sample distribution of this ratio for unassigned days. For 2008, the mean and standard deviation for this ratio amount to 2.3 and 2.4, respectively. For 2010, the mean equals 1.85, and the

\footnotetext{
${ }^{22}$ We add an increment of one gallon to each zero-usage observation before taking logs

${ }^{23}$ These comparison tables are available from the authors upon request
} 
standard deviation is 1.7. According to TMWA, indoor use is higher in summer for the typical household due to factors such as a larger average daily household size as school and college-age children spend more time at home, a higher level of outdoor and athletic activities, increasing water use for drinking, cleaning, laundry, and showers, increased use for the watering of indoor plants, and water use for cooling units. The lower average for 2007 is likely due to the slightly cooler summer that year, as described in the main text.

3. We interpret the above results as indicative of the typical household in the Reno / Sparks area consuming approximately twice as much water per day for non-irrigation purposes in summer than in winter. Based on the standard deviations for the FAFC segment given above, we would further expect daily non-irrigation use for any household not to exceed a ratio to winter use in excess of $3 * 2.4=7.2$ in 2008 and of $3 * 1.7=5.1$ in 2010 .

4. For our final classification step we generally adopt the cluster analysis results based on absolute use, but we recode all observations flagged as "non-watering" days that exceed the three-standard deviation thresholds given above as "watering days". This results in 19,479 changes (8.2 percent of observations originally flagged as non-watering) for the 2008 data, and 17,818 changes (8.6 percent of observations originally flagged as non-watering) for the 2010 set. These recoded observations are likely associated with households that employ some daily baseline watering system, as mentioned above. Due to the latency of the baseline irrigation the cluster analysis fails to identify these non-sprinkler days as irrigation days. Adding information on winter use to our analysis allows us to correct this shortcoming. 


\section{Appendix D. Details on Econometric Specification and Results}

The household and climate regressors in the frequency equation are: log of lot size in square feet ("lnland"), log of tax-assessed land value ("lnvalue"), the weekly average of, respectively, daily minimum and maximum temperature ("mintemp", "maxtemp"), the weekly average of daily average wind in knots ("avgwind"), the weekly average of maximum daily sustained wind ("maxwind"), and total weekly growing degree days ("gdd"). For a given calendar day, the latter is computed as (maximum daily temperature + minimum daily temperature)/2-50. All climate indicators are measured in units of 10 for a more balanced scaling of the regressor matrix.

Equations two (weekly use) and three (weekly peak) include the additional home features log of square footage ("lnsf"), number of bedrooms, number of water fixtures, and age plus age squared. The dropped climate variables (for identification purpose) are "mintemp", "maxtemp", and "gdd".

The full results for equations two and three are given in TableD.11. 
Table D.11: Estimation results for use and peak equations, Bayesian model

\begin{tabular}{|c|c|c|c|c|c|c|}
\hline & \multicolumn{3}{|c|}{ weekly use } & \multicolumn{3}{|c|}{ weekly peak } \\
\hline & mean & std. & $\operatorname{prob}(>0)$ & mean & std. & $\operatorname{prob}(>0)$ \\
\hline constant & -10.766 & $(0.773)$ & 0.000 & -12.706 & $(0.766)$ & 0.000 \\
\hline freq1 & 0.392 & $(0.025)$ & 1.000 & 0.883 & $(0.026)$ & 1.000 \\
\hline freq2 & 0.584 & $(0.025)$ & 1.000 & 0.980 & $(0.026)$ & 1.000 \\
\hline freq3 & 0.720 & $(0.026)$ & 1.000 & 0.989 & $(0.027)$ & 1.000 \\
\hline freq4 & 0.821 & $(0.029)$ & 1.000 & 0.992 & $(0.031)$ & 1.000 \\
\hline freq 567 & 0.967 & $(0.036)$ & 1.000 & 1.048 & $(0.036)$ & 1.000 \\
\hline $\mathrm{SB} *$ freq 2 & 0.208 & $(0.066)$ & 1.000 & 0.379 & $(0.068)$ & 1.000 \\
\hline $\mathrm{SB} *$ freq 3 & 0.197 & $(0.066)$ & 0.999 & 0.334 & $(0.068)$ & 1.000 \\
\hline $\mathrm{SB} *$ freq 4 & 0.179 & $(0.068)$ & 0.995 & 0.307 & $(0.071)$ & 1.000 \\
\hline $\mathrm{SB} *$ freq 567 & 0.200 & $(0.071)$ & 0.999 & 0.233 & $(0.072)$ & 0.999 \\
\hline lnland & 0.389 & $(0.010)$ & 1.000 & 0.439 & $(0.011)$ & 1.000 \\
\hline $\operatorname{lnsf}$ & 0.170 & $(0.033)$ & 1.000 & 0.154 & $(0.036)$ & 1.000 \\
\hline lnvalue & 0.294 & $(0.028)$ & 1.000 & 0.344 & $(0.030)$ & 1.000 \\
\hline fixtures & -0.002 & $(0.003)$ & 0.324 & -0.005 & $(0.004)$ & 0.079 \\
\hline bedrooms & 0.042 & $(0.009)$ & 1.000 & 0.032 & $(0.009)$ & 1.000 \\
\hline age & 0.218 & $(0.011)$ & 1.000 & 0.280 & $(0.012)$ & 1.000 \\
\hline age2 & -0.020 & $(0.001)$ & 0.000 & -0.025 & $(0.002)$ & 0.000 \\
\hline avgtemp & 0.051 & $(0.081)$ & 0.735 & -0.007 & $(0.079)$ & 0.470 \\
\hline avgwind & -0.070 & $(0.453)$ & 0.442 & -0.064 & $(0.462)$ & 0.453 \\
\hline maxwind & 0.050 & $(0.184)$ & 0.615 & 0.008 & $(0.188)$ & 0.506 \\
\hline avgwind $*$ SB & -0.222 & $(0.563)$ & 0.349 & 0.002 & $(0.575)$ & 0.500 \\
\hline maxwind $* \mathrm{SB}$ & 0.032 & $(0.199)$ & 0.567 & -0.058 & $(0.204)$ & 0.386 \\
\hline year2010 & 0.185 & $(0.740)$ & 0.593 & -0.178 & $(0.730)$ & 0.403 \\
\hline freq $1 * 2010$ & -0.010 & $(0.036)$ & 0.393 & -0.009 & $(0.036)$ & 0.385 \\
\hline freq $2 * 2010$ & 0.034 & $(0.035)$ & 0.837 & 0.073 & $(0.035)$ & 0.978 \\
\hline freq $3 * 2010$ & 0.045 & $(0.036)$ & 0.895 & 0.071 & $(0.036)$ & 0.977 \\
\hline freq $4 * 2010$ & 0.053 & $(0.041)$ & 0.901 & 0.092 & $(0.041)$ & 0.990 \\
\hline freq567* 2010 & 0.038 & $(0.049)$ & 0.786 & 0.064 & $(0.048)$ & 0.909 \\
\hline $\mathrm{SB} *$ freq $3 * 2010$ & -0.052 & $(0.144)$ & 0.361 & -0.257 & $(0.147)$ & 0.039 \\
\hline $\mathrm{SB} *$ freq $4 * 2010$ & -0.049 & $(0.146)$ & 0.357 & -0.244 & $(0.150)$ & 0.049 \\
\hline $\mathrm{SB} *$ freq $567 * 2010$ & -0.041 & $(0.147)$ & 0.395 & -0.200 & $(0.151)$ & 0.088 \\
\hline avgtemp $* 2010$ & -0.025 & $(0.082)$ & 0.391 & 0.016 & $(0.080)$ & 0.583 \\
\hline avgwind $* 2010$ & 0.333 & $(0.486)$ & 0.76 & 0.515 & $(0.500)$ & 0.848 \\
\hline maxwind $* 2010$ & -0.109 & $(0.187)$ & 0.258 & -0.143 & $(0.192)$ & 0.240 \\
\hline avgwind $* \mathrm{SB} * 2010$ & -0.020 & $(0.063)$ & 0.372 & -0.033 & $(0.065)$ & 0.304 \\
\hline maxwind * SB * 2010 & 0.010 & $(0.021)$ & 0.688 & 0.021 & $(0.021)$ & 0.837 \\
\hline
\end{tabular}




\section{Appendix E. Independent Random Effects Regressions}

If the random household effects were not correlated across the three equations, the parameters in the use and peak models could in theory be consistently estimated via simple, independent random effects regressions. For the coefficients in the mean function consistency in such a naïve independent framework would hold even if equations two and three were correlated, as long as their respective correlations with equation one is truly zero. This is because the dependent variable of equation one, weekly watering frequency, enters the other two equations on the right hand side (in form of binary indicators), and would thus cause endogeneity problems if there existed a link between equation one and the other two models via the unobservable household effects.

From Table 5 in the main text we see that $\rho_{13}$ is negligible with large posterior uncertainty, but $\rho_{12}$, while small, is positive and estimated with relatively high precision. To examine to what extent ignoring this correlation would affect parameter estimates, we run two independent random effects (RE) regressions for weekly use and peak with the exact same regressors as in our Bayesian Hierarchical Exponential (HE) models. The dependent variables are in log-form.

If endogeneity is not an issue, the two frameworks, Bayesian HE, and classical RE, should produce asymptotically identical results for the following reasons: (i) both are based on the same log-linear parameterized mean function, which assures the same interpretation for marginal effects, (ii) the normal density, which forms the basis for the RE regressions, and the exponential density which underlies the HE model, are both in the family of linear exponential distributions. Therefore, a mis-specification of the (combined) variance of error terms in the likelihood function should not affect consistency of coefficient estimates in the parameterized mean function (see e.g. Cameron and Trivedi, 2005, ch.5), and (iii) while the RE regression has an additional normally distributed idiosyncratic error, both preliminary runs of an expanded Bayesian model and the RE results indicate that the variance of that error term is small compared to the variance of the household effect. ${ }^{24}$ Finally, with over 100,000 observations, we would expect good asymptotic properties from both frameworks.

Table E.12 depicts the full results for the RE regressions. Comparing these results to the posterior means in Table 1, we see that the RE models systematically under-estimate the incremental increase in use and peak at any frequency for SB-type weeks (variables "SB*freq2" through "SB*freq567"). Expressed in percentage terms, this bias is of considerable magnitude, ranging from $7-11 \%$ for use and $15-21 \%$ for peak. Furthermore, the RE models estimates pure policy effects for use peak ("year2010") that are 30-40\% larger, respectively, than the small effects produced by the correlated Bayesian system.

Finally, the RE model under-estimates the reduction in peak for SB-types compared to 2008 ("SB*freq3*2010" through "SB*freq567*2010") by approximately $5 \%$. We thus conclude that the additional complexitities in estimation from switching to a fully correlated triple-equation system are justified for our application.

\footnotetext{
${ }^{24}$ The RE output indicates that $82-86 \%$ of total error variability is assigned to the household effect.
} 
Table E.12: Estimation results for the independent RE regressions

\begin{tabular}{|c|c|c|c|c|c|c|}
\hline & \multicolumn{3}{|c|}{ weekly use } & \multicolumn{3}{|c|}{ weekly peak } \\
\hline & mean & std. & & mean & std. & \\
\hline constant & -8.039 & $(0.255)$ & $* * *$ & -10.186 & $(0.301)$ & $* * *$ \\
\hline freq1 & 0.457 & $(0.006)$ & $* * *$ & 0.870 & $(0.008)$ & $* * *$ \\
\hline freq2 & 0.669 & $(0.006)$ & $* * *$ & 0.980 & $(0.008)$ & $* * *$ \\
\hline freq3 & 0.818 & $(0.007)$ & $* * *$ & 1.026 & $(0.008)$ & $* * *$ \\
\hline freq 4 & 0.935 & $(0.008)$ & $* * *$ & 1.056 & $(0.009)$ & $* * *$ \\
\hline freq 567 & 1.076 & $(0.009)$ & $* * *$ & 1.118 & $(0.011)$ & $* * *$ \\
\hline $\mathrm{SB} *$ freq 2 & 0.101 & $(0.015)$ & $* * *$ & 0.186 & $(0.019)$ & $* * *$ \\
\hline $\mathrm{SB} *$ freq 3 & 0.099 & $(0.015)$ & $* * *$ & 0.151 & $(0.019)$ & $* * *$ \\
\hline $\mathrm{SB} *$ freq 4 & 0.089 & $(0.016)$ & $* * *$ & 0.116 & $(0.019)$ & $* * *$ \\
\hline $\mathrm{SB} *$ freq 567 & 0.136 & $(0.016)$ & $* * *$ & 0.093 & $(0.020)$ & $* * *$ \\
\hline lnland & 0.426 & $(0.009)$ & $* * *$ & 0.482 & $(0.009)$ & $* * *$ \\
\hline $\operatorname{lnsf}$ & 0.258 & $(0.027)$ & $* * *$ & 0.266 & $(0.030)$ & $* * *$ \\
\hline lnvalue & 0.134 & $(0.019)$ & $* * *$ & 0.176 & $(0.022)$ & $* * *$ \\
\hline fixtures & 0.005 & $(0.003)$ & $* * *$ & 0.001 & $(0.003)$ & \\
\hline bedrooms & 0.021 & $(0.007)$ & $* * *$ & 0.012 & $(0.008)$ & \\
\hline age & 0.019 & $(0.001)$ & $* * *$ & 0.025 & $(0.001)$ & $* * *$ \\
\hline age2 & 0.000 & $(0.000)$ & $* * *$ & 0.000 & $(0.000)$ & $* * *$ \\
\hline avgtemp & 0.011 & $(0.002)$ & $* * *$ & 0.007 & $(0.002)$ & $* * *$ \\
\hline avgwind & -0.026 & $(0.011)$ & $* * *$ & -0.020 & $(0.013)$ & \\
\hline maxwind & 0.015 & $(0.004)$ & $* * *$ & 0.010 & $(0.005)$ & $*$ \\
\hline avgwind $* \mathrm{SB}$ & -0.014 & $(0.013)$ & & -0.003 & $(0.016)$ & \\
\hline $\operatorname{maxwind} * \mathrm{SB}$ & 0.002 & $(0.004)$ & & -0.003 & $(0.006)$ & \\
\hline year2010 & 0.530 & $(0.174)$ & $* * *$ & 0.288 & $(0.215)$ & \\
\hline freq $1 * 2010$ & -0.004 & $(0.009)$ & & 0.007 & $(0.011)$ & \\
\hline freq $2 * 2010$ & 0.013 & $(0.009)$ & & 0.040 & $(0.011)$ & $* * *$ \\
\hline freq $3 * 2010$ & 0.015 & $(0.009)$ & & 0.045 & $(0.011)$ & $* * *$ \\
\hline freq $4 * 2010$ & 0.026 & $(0.010)$ & $* *$ & 0.063 & $(0.013)$ & $* * *$ \\
\hline freq567* 2010 & 0.006 & $(0.012)$ & & 0.031 & $(0.015)$ & $* *$ \\
\hline $\mathrm{SB} *$ freq $3 * 2010$ & -0.002 & $(0.033)$ & & -0.164 & $(0.041)$ & $* * *$ \\
\hline $\mathrm{SB} *$ freq $4 * 2010$ & -0.005 & $(0.034)$ & & -0.147 & $(0.042)$ & $* * *$ \\
\hline $\mathrm{SB} *$ freq $567 * 2010$ & -0.009 & $(0.034)$ & & -0.128 & $(0.042)$ & $* * *$ \\
\hline avgtemp * 2010 & -0.007 & $(0.002)$ & $* * *$ & -0.004 & $(0.002)$ & $*$ \\
\hline avgwind * 2010 & 0.043 & $(0.012)$ & $* * *$ & 0.051 & $(0.014)$ & $* * *$ \\
\hline maxwind * 2010 & -0.019 & $(0.005)$ & $* * *$ & -0.021 & $(0.006)$ & $* * *$ \\
\hline avgwind * SB * 2010 & -0.021 & $(0.015)$ & & -0.027 & $(0.018)$ & \\
\hline maxwind * SB * 2010 & 0.009 & $(0.005)$ & $* *$ & 0.016 & $(0.006)$ & $* * *$ \\
\hline
\end{tabular}




\section{References}

Bauder, J., 2000. How much irrigation water do you lose when it's windy? Montana State University Communications Services, July 26, 2000; accessed on Oct. 14, 2013, via http://www.montana.edu/cpa/news/wwwpb-archives/ag/baudr258.html.

Bento, A., Kaffine, D., Roth, K., Zaragoza, M., 2011. The unintended consequences of regulation in the presence of competing externalities: Evidence from the transportation sector. Working Paper, Charles H. Dyson School of Applied Economics and Management, Cornell University.

Brennan, D., Tapsuwan, S., Ingram, G., 2007. The welfare costs of urban outdoor water restrictions. The Australian Journal of Agricultural and Resource Economics 51, 243-261.

Cameron, C., Trivedi, P., 2005. Microeconometrics: Methods and Applications. Cambridge.

Chib, S., Greenberg, E., Winkelmann, R., 1998. Posterior simulation and Bayes factors in panel count data models. Journal of Econometrics 86, 33-54.

Cromwell, J., Smith, J., Raucher, R., 2007. Implication of climate change for urban water utilities. Technical Report. Association of Metropolitan Water Agencies.

Davis, L., Kahn, M., 2010. International trade in used vehicles: The environmental consequences of NAFTA. American Economic Journal: Economic Policy 2.

Duble, R., $2013 . \quad$ Water management on turfgrasses. Texas Cooperative Extension; accessed on Oct. 14, 2013, via http://aggie-horticulture.tamu.edu/archives/parsons/turf/publications/water.html.

Felder, S., Rutherford, T., 1993. Unilateral CO2 reductions and carbon leakage: The consequences of international trade in oil and basic materials. Journal of Environmental Economics and Management $25,162-176$.

Fowlie, M., 2009. Incomplete environmental regulation, imperfect competition, and emissions leakage. American Economic Journal: Economic Policy 1, 72-112.

Goulder, L., Jacobsen, M., van Benthem, A., 2012. Unintended consequences from nested state and federal regulation: The case of the Pavley greenhouse-gas-per-mile limits. Journal of Environmental Economics and Management 63, 187-207.

Goulder, L., Stavins, R., 2011. Challenges from state-federal interactions in US climate change policy. American Economic Review: Papers and Proceedings 101, 253-257.

Griffin, R., Mjelde, J., 2000. Valuing water supply reliability. American Journal of Agricultural Economics 82, 414-426.

Halvorsen, R., Palmquist, R., 1980. The interpretation of dummy variables in semilogarithmic equations. American Economic Review 70, 474-475.

Hausman, J., Hall, B., Grilliches, Z., 1984. Economic models for count data with and application to the patents-R\&D relationship. Econometrica 52, 909-938. 
Hensher, D., Shore, N., Train, K., 2006. Water supply security and willingness to pay to avoid drought restrictions. The Economic Record 82, 56-66.

Howe, C., Smith, M., 1994. The value of water supply reliability in urban water systems. Journal of Environmental Economics and Management 26, 19-30.

MacQueen, J., 1967. Some methods for classification and analysis of multivariate observations, in: Cam, L.M.L., Neyman, J. (Eds.), Fifth Berkeley Symposium on Mathematical Statistics and Probability, University of California Press, Berkeley, CA. pp. 281-297.

Mansur, E., Olmstead, S., 2007. The value of scarce water: Measuring the inefficiency of municipal regulations. NBER working paper No. 13513.

Massart, D., Plastria, E., Kaufman, L., 1983. Non-hierarchical clustering with MASLOC. Pattern Recognition 16, 507-516.

McGuinness, M., Ellermann, A., 2008. The effects of interactions between federal and state climate policies. MIT Center for Energy and Environmental Policy Working Paper No. WP-2008-004.

Munkin, M., Trivedi, P., 2003. Bayesian analysis of a self-selection model with multiple outcomes using simulation-based estimation: An application to the demand for healthcare. Journal of Econometrics 114, 197-220.

Olmstead, S., Hanemann, W., Stavins, R., 2007. Water demand under alternative price structures. Journal of Environmental Economics and Management 54, 181-98.

Renwick, M., Archibald, S., 1998. Demand side management policies for residential water use: Who bears the conservation burden? Land Economics 74, 343-359.

Renwick, M., Green, R., 2000. Do residential water demand side management policies measure up? An analysis of eight California water agencies. Journal of Environmental Economics and Management 40, 37-55.

Rider, P., 1953. Truncated Poisson distributions. Journal of the American Statistical Association $48,826-830$.

Shaw, D., Maidment, D., 1987. Intervention analysis of water use restrictions, Austin, Texas. Water Resources Bulletin 23, 1037-46.

Tanner, M., Wong, W., 1987. The calculation of posterior distributions by data augmentation. Journal of the American Statistical Association 82, 528-550.

Timmins, C., 2003. Demand-side technology standards under under inefficient pricing regimes. Environmental and Resource Economics 26, 107-124.

U.N. World Water Assessment Programme, 2009. Water in a changing world: Facts and figures. Technical Report. United Nations.

U.S. Environmental Protection Agency, 2002. Community water system survey 2000. Technical Report EPA 815-R-02-005A. United States Environmental Protection Agency, Office of Water. 
U.S. Environmental Protection Agency, 2008a. Water supply and use in the United States. Technical Report EPA 832-F-06-006. United States Environmental Protection Agency.

U.S. Environmental Protection Agency, 2008b. Your grass can be greener. Technical Report EPA 832-F-06-028. United States Environmental Protection Agency.

U.S. Environmental Protection Agency, 2008c. Outdoor water use in the United States. Technical Report EPA 832-F-06-005. United States Environmental Protection Agency.

Vinod, H., 1969. Integer programming and the theory of grouping. Journal of the American Statistical Association 64, 506-519.

Worthington, A., Hoffman, M., 2008. An empirical survey of residential water demand modelling. Journal of Economic Surveys 22, 842-871. 